University of Rhode Island

DigitalCommons@URI

Open Access Dissertations

2020

\title{
MULTICULTURAL RESEARCH IN FORENSIC PSYCHOLOGY: WHERE ARE WE NOW?
}

Rebecca J. Aguiar

University of Rhode Island, rebeccanelson87@gmail.com

Follow this and additional works at: https://digitalcommons.uri.edu/oa_diss

\section{Recommended Citation}

Aguiar, Rebecca J., "MULTICULTURAL RESEARCH IN FORENSIC PSYCHOLOGY: WHERE ARE WE NOW?" (2020). Open Access Dissertations. Paper 1189.

https://digitalcommons.uri.edu/oa_diss/1189

This Dissertation is brought to you for free and open access by DigitalCommons@URI. It has been accepted for inclusion in Open Access Dissertations by an authorized administrator of DigitalCommons@URI. For more information, please contact digitalcommons-group@uri.edu. 
MULTICULTURAL RESEARCH IN FORENSIC PSYCHOLOGY: WHERE ARE WE NOW?

BY

REBECCA J. AGUIAR

A DISSERTATION SUBMITTED IN PARTIAL FULFILLMENT OF THE REQUIREMENTS FOR THE DEGREE OF

DOCTOR OF PHILOSOPHY

IN

CLINICAL PSYCHOLOGY

UNIVERSITY OF RHODE ISLAND

2020 


\title{
DOCTOR OF PHILOSOPHY DISSERTATION
}

\author{
OF \\ REBECCA J. AGUIAR
}

APPROVED:

Dissertation Committee

Major Professor

David Faust

Joseph Rossi

Jill Doerner

Nasser H. Zawia

Dean, The Graduate School

UNIVERSITY OF RHODE ISLAND 


\begin{abstract}
Introduction: Forensic psychology is one of the fastest-growing areas in psychology. Over the past few decades, forensic psychology research has had significant impact on legal outcomes and clinical practice. Further, the population served by forensic psychologists has become increasingly diverse. However, past reviews of forensic psychology research indicates cultural factors are not always prominent variables of interest. Accordingly, this study examined how cultural variables are captured within forensic psychology research, and identified the proportion of articles in major forensic psychology journals focused on multicultural research. This study aimed to extend previous work by examining the incorporation of cultural variables capturing a number of sociocultural groups, as well as trends in multicultural considerations within forensic psychology. The primary methodology that was applied - content analysis - is frequently used to study scholarly work and trends within psychology. As was intended here, content analysis often provides insight, reflection, feedback, and critique, and highlights areas for growth and continued development. Methods: Given the present study's focus on forensic psychology research, journal selection was confined to outlets that exclusively or primarily address forensic psychology topics. Eight specialist journals were selected as they are among the most frequently cited within the field of forensic psychology, suggesting that articles published within these journals are considered to be influential and relevant to psychology and law scholars. All original articles from the above eight identified journals published from 2015 to 2017 were pooled for article selection. As the present study was interested in examining the incorporation of cultural variables
\end{abstract}


into forensic psychology research, theoretical, review, and research articles were selected for inclusion in the sample. Sixty articles were randomly selected to create the subset of articles from the eight journals to create the dataset of articles to be coded. This random selection process provided an equally distributed, likely representative, and sufficiently large sample of 480 articles comprising the total data base for the analyses. To examine how culture is captured in these articles, this study focused on the presence of the following cultural groups as they are used as topic areas or variables within forensic psychology research: age/generation, race/ethnicity, religion/spirituality, language, sexual orientation, gender identity and diversity, socioeconomic status, ability/disability status, neighborhood, immigration, and indigenous heritage. Articles were coded by four researchers who used a coding sheet and accompanying codebook designed for the purposes of this study. Acceptable interrater reliability was achieved as reflected in kappa coefficients ranging from .84 to .98 for items. All sections of articles were coded to examine inclusion of cultural variables. Additionally, articles were categorized as multiculturally-focused when: 1) theoretical and review articles had cultural variables mentioned in the title and/or in the stated aims/purpose of the article; or 2) research articles had cultural variables present in the title and/or aims and hypotheses of the study. Coding sheet items were designed to collect categorical data and descriptive analyses, specifically frequency statistics, were conducted to address study aims. Results: The final sample was comprised of 462 articles; 76 articles were classified as theoretical or review papers $(2015, n=22 ; 2016, n=24 ; 2017, n=30)$, and 386 as research articles $(2015, n=$ $118 ; 2016, n=148 ; 2017, n=120$ ). Results revealed a mean of about three cultural 
variables incorporated into articles as a whole, with a standard deviation of 1.6, and a range of 0 to 9 . Almost all articles $(96 \%)$ incorporated at least one cultural variable. Out of the study sample of 462 articles, $44 \%(n=203)$ were classified as multiculturally-focused. Areas of notable strengths include high rates of cultural inclusion within sample demographics and common incorporation of certain variables, specifically for age/generation, gender identity, and race/ethnicity. Findings suggest that forensic psychology research has a limited and selective focus of cultural inclusion. General inclusion of cultural variables in any section of articles was notably higher than rates of multiculturally-focused articles. Additionally, results suggest a disproportionate representation of cultural variables within reporting of participant demographics and an overrepresentation of majority groups. Conclusions: It is hoped the present study serves as a call to action for the field of forensic psychology. The current findings have identified a number of areas for improvement of cultural research within forensic psychology; mainly, that the field needs to better incorporate culture into all aspects of its research. This study generated both positive outcomes but also areas of concern, and it is hoped that in particular, identifying areas requiring attention will challenge the field to grow, adapt, and develop in its approach to conducting cultural research. 


\section{ACKNOWLEDGMENTS}

First, I wholeheartedly thank Dr. David Faust for his mentorship and dedication to my professional development. Over the past six years, he has worked tirelessly to make me a better writer, scholar, clinician, and person. David has shown such kindness and caring for my family and personal well-being. He never doubted me, even when I doubted myself. He challenged me to develop my intellect and pushed me to explore topics I may have otherwise avoided from fear of failure, and in doing so has made me a little more fearless. His unwavering support and encouragement has meant everything to me. I will forever consider it an honor and a privilege to have had the opportunity to learn from one of the greatest scholars in the field.

Further, I thank my doctoral committee - Drs. Joseph Rossi and Jill Doernerand dissertation defense chair - Dr. Ginette Ferszt - for their valuable feedback, provided guidance, and shared enthusiasm for this project. And I thank my undergraduate research team - Allison Tobar-Santamaria, B.S., B.A., Leslie Hammer, B.S., Chrissy Wagner, B.S., and Ashley Wagner, B.A. - for their diligent work, collaborative effort, and dedication.

I have been incredibly fortunate to have a number of mentors over the years that have helped to foster my intellectual curiosity and have supported my efforts toward earning a doctorate degree. Words cannot express how grateful I am to the following individuals: Dr. Sheila K. Grant, Dr. Frank DiCataldo, Dr. Laura Guy, Dr. Gina Vincent, Dr. Tom Grisso, and Dr. Nicole Weiss. Without you, I would not have 
made it to this point in my career and your support and influence will never be forgotten.

Thank you to my siblings, extended family members, and friends for being so understanding over the past ten years. You always supported me pursuing my dreams even when it meant being thousands of miles apart and only seeing each other twice a year. Your love, sacrifice and endless questions of what my dissertation is on and when I will be done, have finally paid off.

To my URI loves - thank you for all of the support, commiserating, and pep talks you have given over the years. I would not have made it through the program without you by my side. Each of you has inspired me and I feel lucky to have you as friends and colleagues for life.

Words cannot describe the gratitude and love I have for my parents and the support they have provided me. They have always pushed me to live up to my potential, something I struggled to believe I had growing up. They taught me to have a strong work ethic, to never give up, and to find purpose in helping others. They have given so much to make sure I achieved my dream to become a psychologist. Through their love, support, and encouragement, I have a blessed life for which I owe them everything.

Finally, I have to thank the two men in my life who have given the most in the pursuit of my professional career. To my stepson, Daven - you may not think you have done anything to support my career, but you are so wrong. Thank you for always understanding when I had to work on nights and weekends, and for making me feel like I was a good parent, especially at times when I felt like I was not doing enough 
for you. Thank you for humoring me every time I told you to trust me because I was going to be a doctor. Most of all, your love, joy, and humor carried me through even the darkest days and reminded me truly the most important thing in life is my family.

Finally, to my husband and life partner, Brian - words cannot express how thankful I am for everything you have done over the past eight years. I don't think you really understood what you were getting into when I told you I wanted to get a doctorate degree, but you gave me unending love and support. I could not have done this without you. You held me when I cried, you celebrated every milestone, you encouraged me to work hard, and you kept me sane and grounded. I am so grateful to have you as my partner and I will love you always. 


\section{TABLE OF CONTENTS}

ABSTRACT

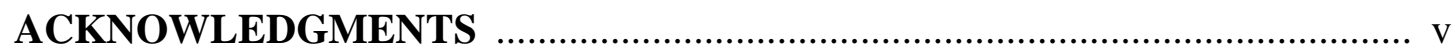

TABLE OF CONTENTS ................................................................... viii

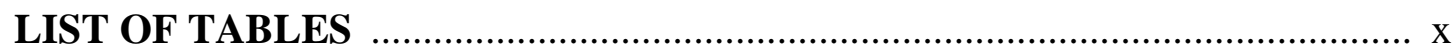

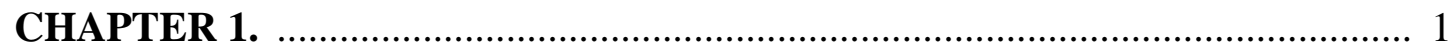

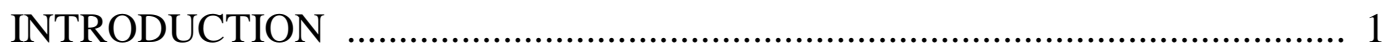

Statement of the Problem .................................................................... 1

Review of the Literature ............................................................... 1

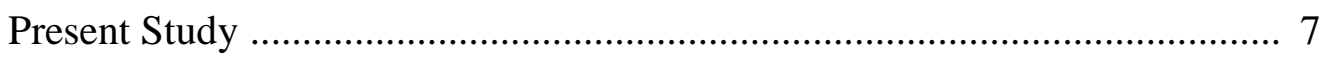

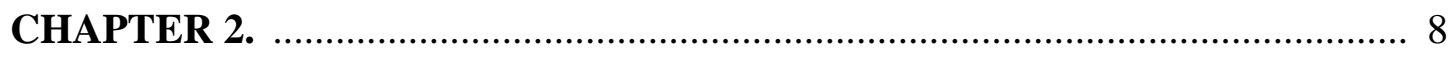

METHODOLOGY ............................................................................... 8

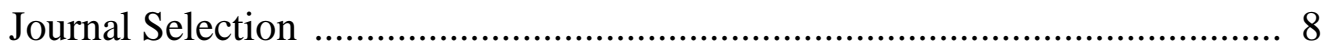

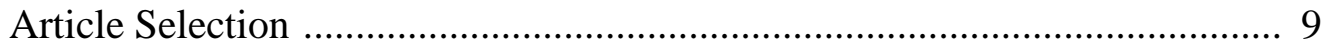

Defining Cultural Variables .............................................................. 12

Procedure …............................................................................ 13

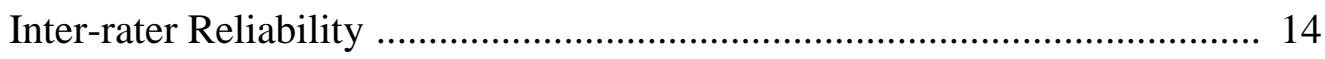

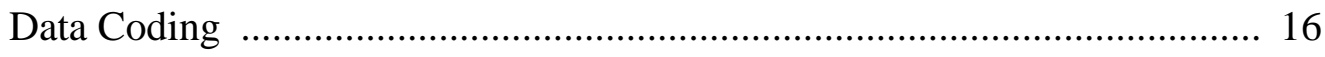

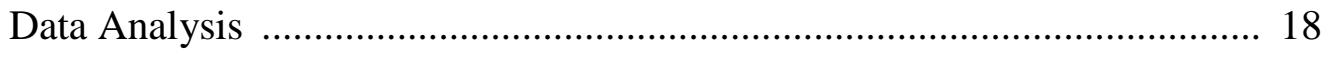

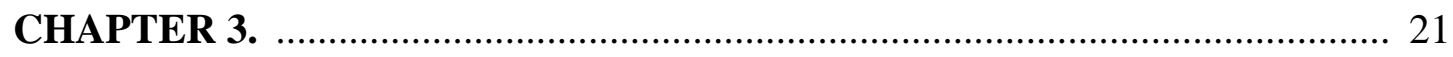

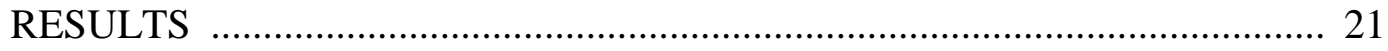

Cultural Inclusion in Forensic Psychology .......................................... 23

Limited and Selective Focus of Cultural Inclusion ............................... 35 


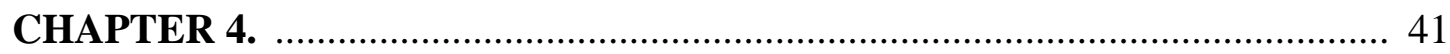

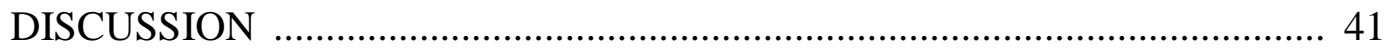

Strengths within Forensic Psychology ............................................... 41

Areas for Growth ..................................................................... 45

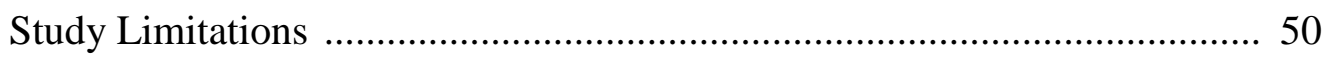

Potential Implications .............................................................. 51

Practical Applications and Future Directions ..................................... 55

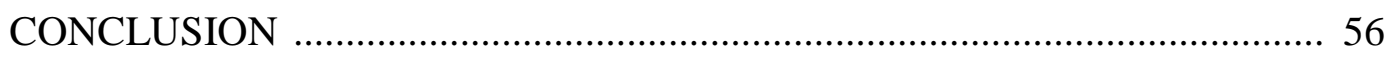

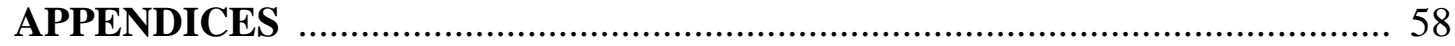

APPENDIX A - Coding Sheet for Articles ........................................... 58

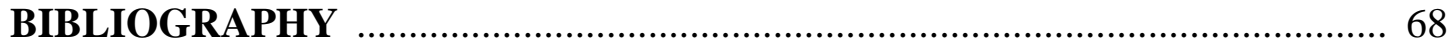




\section{LIST OF TABLES}

TABLE

PAGE

Table 1. Proportion of articles included in the random selection process

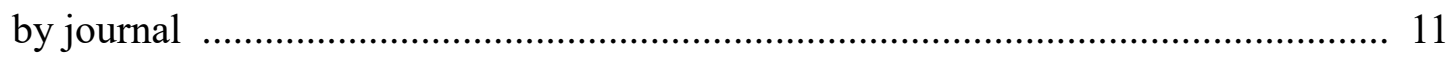

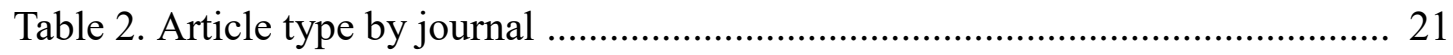

Table 3. Representation of cultural variable inclusion ....................................... 23

Table 4. Cultural variable inclusion across article sections ............................... 24

Table 5. Rates of inclusion by specific cultural variables .................................. 25

Table 6. Cultural variable inclusion within reported participant demographics by

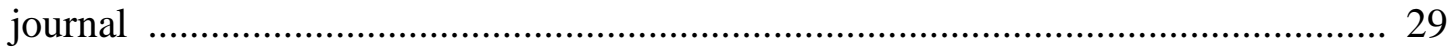

Table 7. Sociocultural identity inclusion for multiculturally-focused articles and

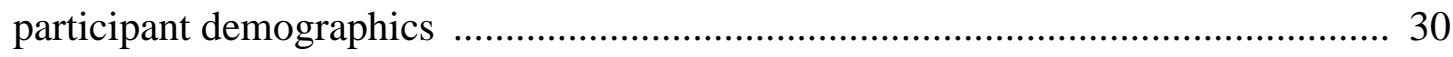

Table 8. Multiculturally-focused articles by journal ......................................... 33

Table 9. Methodology and data analytic approaches in multiculturally-focused

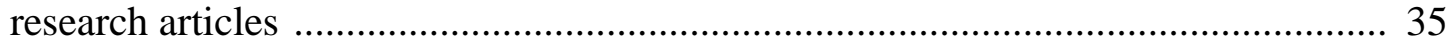




\section{Chapter 1.}

\section{INTRODUCTION}

\section{Statement of the Problem}

Forensic psychology is one of the fastest-growing areas in psychology. Over the past few decades, forensic psychology research has had significant impact on legal outcomes and clinical practice. Further, the population served by forensic psychologists has become increasingly diverse. However, past reviews of forensic psychology research indicates cultural factors are not always prominent variables of interest. Accordingly, this study examined how cultural variables are captured within forensic psychology research, and identified the proportion of articles in major forensic psychology journals focused on multicultural research. This study aimed to extend previous work (e.g., Carter and Forsyth, 2007; Padilla, Miller, \& Broadus, 2008) by examining the incorporation of cultural variables capturing a number of sociocultural groups, as well as trends in multicultural considerations within forensic psychology.

\section{Review of the Literature}

Forensic psychology focuses on the intersection of psychology and law and addresses psychological questions and issues that arise in legal proceedings (Heilbrun \& Brooks, 2010; Otto \& Heilbrun, 2002). Forensic psychologists serve as consultants, experts, evaluators, and treatment providers at almost every point of the legal process. In addition to professional and clinical practice, forensic psychology also includes research that examines aspects of human behavior related to the legal process and the criminal justice system (Bartol \& Bartol, 2017). 
Over the past few decades, forensic psychology has experienced tremendous growth. Although psychologists and other mental health professionals had been involved in issues within the legal system for many years, forensic psychology did not begin to emerge as a formal field with distinct clinical and research interests until the early 1970's (Heilbrun \& Brooks, 2010). Since that time, forensic psychology has made substantial gains, including a growing number of publications and the development of numerous journals dedicated to pertinent issues in psychology and the law (e.g., Law and Human Behavior; Behavioral Sciences and the Law). In 2010, Heilbrun and Brooks noted that the "field has matured: the recognition of the importance of the foundational science [of forensic psychology] is stronger, and we are closer to identifying best practices across a range of legal contexts that are addressed by forensic psychology research and practice" (p. 227).

Forensic psychology research has become increasingly important to a range of legal issues. Such research helps to inform crucial decisions and activities from the beginning to the end of the legal process, such as determining possible transfer of adolescents to adult criminal court, assessing individuals' potential danger to society, and designing treatment that increases the likelihood of rehabilitation and lowers the chance for future offending. As this research is applied to important psycholegal questions that have significant real-world effects, it is crucial to ensure that the methodology used to conduct these studies reflects sound practice and careful consideration of the issues at hand.

\section{Diversity within Forensic Psychology}


Multicultural considerations are of particular concern within forensic psychology research because the criminal justice system is comprised of individuals with diverse backgrounds and cultural identities, including race, ethnicity, age, gender, and socioeconomic status (Carson, 2015; Carter \& Forsyth, 2007; Kaeble, Maruschak, \& Bonczar, 2015). There has been increased awareness, both scholarly and socially, that racial and ethnic minority groups have become disproportionately represented within the criminal justice system through decades of discriminatory policies, procedures, and practices (Sampson \& Lauritsen, 1997; Pettit \& Western, 2004). Research suggests that racial and ethnic minority groups account for $43 \%$ to $59 \%$ of all individuals that forensic psychologists serve (Carson, 2015; Kaeble et al., 2015). Moreover, research indicates that the number of other cultural minority/marginalized groups such as women, LBGTQ individuals, and individuals with differing abilities (i.e., cognitive and physical), has been rapidly growing over the past two decades (e.g., Brewer \& Heitzeg, 2008; Mogul, Ritchie, \& Whitlock, 2011). It is evident that the population of interest for the field is inherently diverse and has individuals from multiple and intersecting sociocultural identities. Moreover, it stands to reason that aspects of culture would impact the application of research broadly and in such key areas as policy development and intervention design. As such, the field of forensic psychology should be interested in, and committed to, routinely incorporating culture into scholarly works.

\section{Multicultural Research in Forensic Psychology}

Although forensic psychology intrinsically focuses on multicultural populations, it appears that multiculturally-focused considerations have not been 
emphasized in many forensic studies (Carter \& Forsyth, 2007; Padilla, Miller, \& Broadus, 2008; Edgar, 2012). Carter and Forsyth (2007) conducted a content analysis examining research articles from forensic psychology journals from 1997 to 2003, and found that $47 \%$ of articles made no mention of race or ethnicity at all, and that a significant proportion of those that did (43\%) mentioned race or culture only when describing the demographics of the sample. Additionally, the researchers were interested in examining the number of articles that included race and culture in-depth; that is, issues related to race and culture were addressed in all sections of the article. Less than $10 \%$ of all 493 articles $(n=47)$ addressed these issues in-depth.

For the small group of articles examining race/culture in-depth, additional coding was conducted to subdivide them into three categories: cultural deprivation, cultural difference, or race-based studies. Carter and Forsyth (2007) found that over $75 \%$ of these articles used a cultural deprivation paradigm, which the researchers referred to as studies focused on cultural deficits or disadvantages present in racial/ethnic minority groups in comparison to White normative groups. Further, 22\% relied on a cultural difference paradigm where differences between racial/ethnic minority groups and the White majority group are related to cultural factors (e.g., values, experiences) and not a result of some deficit or inadequacy. Finally, none of the articles in which race/culture were examined in-depth used a race-based paradigm, which includes research focused on understanding the influence of within-group differences in racial/ethnic identity on various outcomes (Carter \& Forsyth, 2007).

Similarly, Padilla and colleagues (2008) conducted a content analysis examining the inclusion of Hispanic populations in forensic psychology research from 
2000 to 2005. In all, they examined 800 articles from leading forensic psychology journals as determined by online journal rankings. As the authors noted, Hispanics have become the largest ethnic minority group in the United States, yet there is little research examining the impact of this rapid growth on the legal system. Although close to $20 \%$ of the articles reviewed discussed ethnicity, only $5.6 \%$ of them discussed Hispanics in relation to the main topic or variables of interest. Like Carter and Forsyth (2007), they found that less than half of the articles included the ethnic composition of their respective samples. Further, Hispanics were identified as participants in only a quarter of all the articles. Finally, $89 \%$ of articles distinguished Hispanics as a unique ethnic group separate from other minority groups. However, $11 \%$ of articles categorized Hispanics as "minority" or "other", grouping them with other ethnic minority groups (Padilla et al., 2008).

Finally, an unpublished doctoral dissertation sought to extend Carter and Forsyth's (2007) work by examining the extent to which forensic psychology journals address race/ethnicity and culture within juvenile populations (Edgar, 2012). Using methodology similar to that of previous studies (Carter \& Forsyth, 2007; Padilla et al., 2008), Edgar (2012) coded all articles from four forensic journals from 2006 to 2011. Coding primarily addressed whether the race/ethnicity of the sample was identified and further discussed or incorporated into the article (i.e., race/ethnicity salient), and if the article specifically identified and addressed juveniles as the perpetrators of crimes (i.e., not child victims) as the topic of interest (i.e., juvenile salient). Of the 1,289 articles analyzed, $15.9 \%(n=204)$ were found to be salient for juvenile forensic populations, $7.8 \%(n=100)$ for race/ethnicity, and only $2 \%(n=30)$ for both 
variables. Results also yielded a significantly higher percentage of juvenile versus adult articles that were race/ethnicity salient. Thus, like other related studies, Edgar (2012) found that cultural variables continued to be under-studied within forensic psychology journals.

The results from these studies seem to conflict directly with the American Psychological Association's (APA) Multicultural Guidelines (2002; 2017). As set forth in the Guidelines, psychologists should strive to conduct culturally appropriate and informed research with explicit attention to, and careful consideration of, culture through all stages of the research process, including development and design, assessment use, data analysis, and interpretation. In contrast, research to date has shown that about half of articles report culture as sample demographics, and that cultural variables are not typically infused into other or all aspects of research studies (Carter \& Forsyth 2007; Padilla et al., 2008). Moreover, the research indicates that racial/ethnic cultural variables are rarely the focus of studies, but when they are, the research treats or conceptualizes racial or cultural background as the underlying issue rather than considering potential systemic racial-cultural bias inherent in the legal system. Further, based on these research findings, it could be inferred that other important cultural identities (e.g., gender identity, sexuality, nation of origin) that influence experiences, treatment, and outcomes within the criminal justice system may also be under-studied. Given the disproportionate representation of diverse and marginalized groups within the criminal justice system, the dearth of literature centered on cultural identities and multicultural methodology within forensic psychology research is particularly concerning. 


\section{Present Study}

Continued examination of the extent to which forensic psychology research is capturing and incorporating culture is critical as the field continues to grow and develop rapidly. As such, this study sought to extend previous work (e.g., Carter and Forsyth, 2007; Padilla et al., 2008) by examining trends in the inclusion and incorporation of cultural variables within research in forensic psychology, and by broadening the range of variables under investigation. The primary methodology that was applied - content analysis - is frequently used to study scholarly work and trends within psychology. As was intended here, content analysis often provides insight, reflection, feedback, and critique, and highlights areas for growth and continued development (Donald \& Ng, 2014; Eford, Miller, Duncan, \& Eford, 2010). Journal and article selection in the current study reflect content analyses procedures used in previous studies examining the inclusion of culture within forensic psychology research (i.e., Carter \& Forsyth, 2007; Padilla et al., 2008).

The first aim of this study was to examine the extent to which cultural variables are captured within contemporary forensic psychology research (Aim 1). Particular attention was directed towards examining how cultural variables are described and conveyed (Aim 1a), and the representation of various sociocultural identities within articles (Aim 1b). Additionally, this study aimed to identify the proportion of multiculturally-focused research articles in major forensic psychology journals (Aim 2) and for research articles, to determine the relative frequency of different study designs, methods, and data analytic techniques (Aim 2a). 


\section{CHAPTER 2.}

\section{METHODOLOGY}

\section{Journal Selection}

Given the present study's focus on forensic psychology research, journal selection was confined to outlets that exclusively or primarily address forensic psychology topics. Moreover, the significant growth in the field and the rising number of forensic psychology-related journals, as well as feasibility concerns, seemed to argue for narrowing inquiry to leading journals. Top-tier journals tend to apply rigorous evaluative criteria and publish high quality work that has a disproportionately greater impact on the field, future research directions, and policy and procedures in the legal arena. If it was not feasible to examine the literature exhaustively, focusing on the most influential journals in the field, which arguably set a standard for research, appeared to be a sensible choice.

Black (2012) examined works cited in six forensic psychology journals in order to identify the most frequently cited journals in the field. Analysis of the collected sample of works cited $(N=21,776)$ published between 2008 to 2010, resulted in 68 journals receiving at least $0.2 \%$ of citations, representing cumulatively $47.3 \%$ of the 21,776 works cited. Within the top 20 journals listed, eight are specialist journals in forensic psychology, with the remaining 12 generalist psychology journals (e.g., Journal of Applied Psychology and Psychological Assessment). Based on Black's findings, these eight journals are among the most frequently cited within the field of forensic psychology, suggesting that articles published within these journals are considered to be influential and relevant to psychology and law scholars. 
Accordingly, the following eight forensic psychology journals were selected for the current study: Law and Human Behavior; Behavioral Sciences and the Law; Criminal Justice and Behavior; Journal of Forensic Psychiatry and Psychology; Psychology, Public Policy and the Law; Psychology, Crime, and Law; Legal and Criminological Psychology; Journal of the American Academy of Psychiatry and the Law.

\section{Article Selection}

All original articles from the above eight identified journals published from 2015 to 2017 were pooled for article selection. As the present study was interested in examining the incorporation of cultural variables into forensic psychology research, theoretical, review, and research articles were selected for inclusion in the sample. These types of articles contribute to the literature by reviewing and critiquing past scholarly research, or by encompassing the original research itself. All other types of journal submissions were excluded, including: editorial introductions, speeches, letters, comments on previously published articles, corrections, replies to critiques, or book reviews.

An initial examination of all articles published in each of the eight journals from 2015 to 2017 was conducted to remove articles meeting the above exclusion criteria. The remaining 1,134 articles were entered into a database that included the journal name, title of the article, volume/issue number, and year published. Review of this initial pooling revealed the number of available articles for sampling varied by journal, ranging from 77 to 229 articles. The majority of journals had 112 to 171 articles available (See Table 1). 
A random selection process would approximate an equally distributed sample, whereas selecting half of all the available articles would increase the likelihood of article inclusion (versus exclusion) resulting from chance. However, achieving this aim would have required selecting around 70 articles from each journal, leading to a disproportionate representation of content from journals with lower numbers of articles. For example, selecting 70 articles from Legal and Criminological Psychology would have resulted in $90 \%$ of their available articles being included in the final sample. Additionally, the random selection process needed to be balanced with feasibility concerns about the number of articles that could be coded.

After multiple number points for random selection were examined, it was concluded that randomly selecting 60 articles from each journal would allow for a total sample $(N=480)$ nearing half of all available articles. Each article was assigned a number and a random number generator then used to select the subset of articles from the eight journals to create the dataset of articles to be coded. This random selection process provided an equally distributed, likely representative, and sufficiently large sample of 480 articles comprising the total data base for the analyses. 
Table 1

Proportion of Articles Included in the Random Selection Process by Journal

\begin{tabular}{lccc}
\hline \multicolumn{1}{c}{ Journals } & $\begin{array}{c}\text { All } \\
\text { available articles }\end{array}$ & $\begin{array}{c}\text { Articles } \\
\text { randomly selected }\end{array}$ & $\begin{array}{c}\text { Proportion of } \\
\text { random selection }\end{array}$ \\
\hline Law and Human Behavior & 163 & 60 & $37.0 \%$ \\
Behavioral Sciences and the Law & 136 & 60 & $44.1 \%$ \\
Journal of Forensic Psychiatry and Psychology & 152 & 60 & $40.0 \%$ \\
Psychology, Public Policy and the Law & 112 & 60 & $54.0 \%$ \\
Criminal Justice and Behavior & 229 & 60 & $26.2 \%$ \\
Psychology, Crime, and Law & 171 & 60 & $35.1 \%$ \\
Legal and Criminological Psychology & 77 & 60 & $78.0 \%$ \\
Journal of the American Academy of Psychiatry and the Law & 94 & 60 & $64.0 \%$ \\
Total & $\mathbf{1 , 1 3 4}$ & $\mathbf{4 8 0}$ & $\mathbf{4 2 . 3 \%}$ \\
\hline
\end{tabular}




\section{Defining Cultural Variables}

Culture is a multifaceted construct, but within cross-cultural theory and research it is commonly defined broadly as a knowledge system - comprised of customs, traditions, beliefs, values, and social expectations that shape individuals' emotions, thoughts, and behavior - that is inherited, transmitted, and reproduced among a group of individuals sharing a common identity (van der Vijver \& Matsumoto, 2010). These identities are thought to be shaped by cultural influences across a range of social groups (APA, 2017; Cho, Crenshaw, \& McCall, 2013). Examples of cultural identities include, but are not limited to, race, ethnicity, gender, socioeconomic status, and age.

Scholars have proposed models and frameworks to conceptualize and summarize the vast array of complex cultural influences to be used in the understanding of multiculturalism and its integration into psychological theory, research, and practice. For example, Hays's ADDRESSING framework (2009) was proposed to remind psychologists of the cultural influences that are important to consider when engaging in culturally competent clinical practice. This acronym represents the following cultural identities: age and generational influences, developmental disabilities, disabilities acquired later in life, religion and spiritual orientation, ethnic and racial identity, socioeconomic status, sexual orientation, indigenous heritage, national origin, and gender (Hays, 2009). Moreover, the APA's current Multicultural Guidelines (APA, 2017) included all of the cultural identities found within Hays' framework when detailing the cultural influences thought to shape identity as it develops across contexts and time. 
Accordingly, this study used the definition of culture detailed above. Additionally, to examine how culture is captured in these articles, this study focused on the presence of the following cultural groups as they are used as topic areas or variables within forensic psychology research: age, generation, race/ethnicity, religion/spirituality, language, sexual orientation, gender identity and diversity, socioeconomic status, ability/disability status, neighborhood, immigration, and indigenous heritage (Hays, 2009; APA, 2017). Further, the presence of various sociocultural identities within these cultural groups was of interest in order to examine how cultural variables were described or conveyed. Sociocultural identities reflected subcategories commonly used to specify or differentiate an individual's self-ascribed or assigned membership within the larger cultural group. For example, sociocultural identities within the cultural variable of gender included (but was not limited to) women/female, men/male, transgender, gender non-conforming, and non-binary. Please see Appendix A for all sociocultural identities included in the present study.

\section{Procedure}

Articles were coded by five researchers: the principal researcher and four undergraduate research assistants (four White women and one Latina woman). A coding sheet and accompanying comprehensive codebook were developed to assist the researchers in coding articles reliably. The coding sheet was designed to evaluate and address questions within each section of an article. All coding materials were developed prior to coding articles in the sample. The research team received approximately eight hours of training related to the following areas: background information on the purpose and relevance of the present study; content analysis coding 
procedures; forensic psychology research topics; cultural research and methodology; and data recording and entry. Additional training was provided as needed during weekly, 1-hour long, research team meetings.

The research team assessed all questions on the coding sheet to identify low inference and high inference items. Separately, each researcher was given two random articles from a 2013 issue of each selected journal $(n=16)$ and completed the coding sheet for these articles, qualitatively noting which items were more difficult, less clear, or took larger amounts of time to complete. Each coder had their own unique set of articles, with no two coders examining the same article at this stage. Through a consensus process, a list of high inference items were created and noted during codebook development to assist in providing coders with adequate instructions and examples. Coders were strongly encouraged to use the "unable to determine" (UD) option whenever rating an item was unclear and might well lead to error. These cases with ambiguous items were determined to require review by the team of coders and resolved by consensus during the entire coding process.

Next, a pool of articles was created by drawing articles from the journals selected for the study, but from the year 2014, and were designated to be used only in the piloting process. This approach ensured that pilot articles would not be needed in the actual study in the event that additional articles from previous years were required to achieve adequate sample size. The initial version of the coding sheet and codebook were piloted with a small number of articles $(n=16)$. These articles were completed independently, and then reviewed by the research team, which discussed disagreements. Based on the initial piloting results, further editing and refinement of 
the codebook, and additional training were required before proceeding to further piloting articles and assessing inter-rater reliability.

\section{Inter-rater Reliability}

Inter-rater reliability was assessed by calculating the kappa statistic of agreement (Fleiss, 1971). Fleiss's kappa measures reliability of agreement between three or more raters when coding categorical variables. Possible kappa values range from -1 to 1 , with 1 indicating absolute agreement, 0 indicating random agreement, and -1 indicating perfect disagreement. Although there is no consensus in the field for kappa coefficient interpretation, the following suggested guidelines (Altman, 1999; Landis \& Koch, 1977) are commonly used: values at or below zero reflect poor agreement, 0.0 to 0.20 slight agreement, $0.21-0.40$ fair agreement, 0.41 to 0.60 moderate agreement, 0.61 to 0.80 substantial agreement, and 0.81 to 1.0 almost perfect agreement.

After additional review of the coding materials and further training was provided, another 16 articles were selected from the pilot article sample and were again independently coded. This set of articles was analyzed for initial inter-rater agreement to determine if the coding sheet and codebook could be finalized. It was pre-determined that the research team would only proceed with the next round of coding when acceptable kappa coefficients had been attained. A kappa coefficient of 0.61 or higher (i.e., substantial agreement) was considered acceptable inter-rater agreement as some research suggests coefficients below 0.60 indicated inadequate agreement among raters and suggests limited confidence in study results (McHugh, 2012). Although 0.61 was set as the minimum threshold for inter-rater agreement, it 
was anticipated that higher coefficients would be obtained as a number of efforts (i.e., training, practice cases, consensus ratings) would be made to increase the likelihood of achieving reliability coefficients closer to substantial interrater agreement.

Resultant kappa coefficients ranged from .82 to .98 for most items. Two items, however, one related to methodology (i.e., study design) and another to the inclusion of cultural variables in data analyses (e.g., cultural variables as covariates, used to explore between group differences, etc.) achieved moderate agreement $(\kappa=.58$ and $\kappa$ $=.45$, respectively). Additional training was provided on these items and information was added to the codebook in an effort to increase accuracy or consistency in coding. Upon completion of additional training and codebook editing, the coding sheet and codebook were finalized and analysis of inter-rater reliability proceeded.

As noted, kappa coefficients reaching or exceeding 0.61 was set as the minimum standard for items in the main study. Items that continued to have lower coefficient values were eliminated. A final analysis of inter-rater reliability was conducted with researchers independently coding 30 randomly selected articles from the sample database of 480 articles. Kappa coefficients for most items indicated substantial to almost perfect agreement $(\kappa=.84$ to $\kappa=.98)$. However, despite providing additional training and information in the codebook, the same two items addressing study design and data analyses still fell below the acceptable threshold $(\kappa=$ .58 and $\kappa=.50)$ and thus were eliminated. Fortunately, a number of retained items seemed likely to capture meaningful data on the methodology and reporting of results for multiculturally focused research articles.

\section{Data Coding}


After adequate inter-rater reliability was achieved and problem items eliminated, research team members were randomly assigned a subset of the 480 articles to code using the finalized coding sheet and codebook. For all articles, essential tracking information was documented, including the journal, article title, volume/issue, page numbers, and the name of the coder and the date the article was coded. Article type (i.e., theoretical/review, or research), the nation of origin of the article (i.e., international country or United States), and the keywords included in the article (i.e., keywords listed or no keywords provided) were also recorded. Articles were examined to determine if cultural variables were mentioned in the title, introduction/literature review, and aims/ hypotheses. Research assistants coded all of the sociocultural identities included within all articles sections for theoretical/review papers, and the specific cultural groups present in the title and aims/hypotheses for research articles. Next, all research articles were coded to capture if the study provided participant demographics (i.e., yes or no), and if so, documented all of the sociocultural identities present in the sample demographics of the article. Please see Appendix A for all items contained in the coding sheet.

To address the second aim of the study, articles were categorized as multiculturally-focused when: 1) theoretical and review articles had cultural variables mentioned in the title and/or in the stated aims/purpose of the article; or 2) research articles had cultural variables present in the title and/or aims and hypotheses of the study. The inclusion of cultural variables in these sections of an article were selected with the rationale that the title and aims of a paper would reflect the intended topic or 
focus of a research endeavor. That is, if cultural factors were pertinent to the purpose of the article, they would likely be included in the title and/or aims.

For research articles that were classified as multiculturally-focused, data were coded from the method/procedure and the analyses/results sections (see Appendix A). Sampling methods were of primary interest related to cultural inclusion in the procedures of a study. Descriptions of procedures for selecting study participants were coded to determine if they reflected purposive or convenience sampling. Purposive sampling techniques have been described as the deliberate choice of participant inclusion based on characteristics relevant to the aims of the study, whereas convenience sampling techniques have been characterized as participants that are easier to access (e.g., close proximity) by researchers (Etikan, Musa, \& Alkassim, 2016). Items coded related to the results section of articles were examining the inclusion (i.e., yes or no) of all sociocultural identities (e.g., age, gender, and race/ethnicity) in the reported results, both within the text and displayed tables within the article.

Finally, for both theoretical/review and research articles, discussion sections were coded to indicate whether lack of inclusion of culture was noted as a limitation (i.e., yes, no, not applicable for multiculturally-focused articles) and if cultural variables were suggested for inclusion in future lines of review or research. Discussion of culture in the limitations and the need to address culture in future research acknowledges difficulties incorporating culture due to any number of factors (e.g., lack of available data, limited access to relevant participants) and its importance in knowledge development. 


\section{Data Analysis}

Coding sheet items were designed to collect categorical data (see Appendix A). Accordingly, descriptive analyses, specifically frequency statistics, were conducted to address study aims. Frequency statistics tally the number of observations in a given category and the percentage of observations in that category out of all observations. These proportions help to describe and summarize data in a manner that facilitates interpretation.

A series of frequency analyses were conducted. The first set of analyses yielded frequency statistics examining the inclusion of cultural variables in contemporary forensic psychology research (Aims 1, 1a, and 1b). When examining the representation of sociocultural identities of research participants, a total of 21 articles were excluded from analyses as they were meta-analyses, systematic reviews, or incorporated case-level participants (e.g., probation offices) that did not contain sample demographics. Next, analyses included research articles categorized as multiculturally-focused to determine their proportion in major forensic psychology journals (Aim 2). Within this subset of articles, research articles were analyzed to examine methodology and reported results (Aim 2a).

Results generated an abundance of rich information and content that would necessitate multiple manuscripts to thoroughly review and discuss. For the purposes of this dissertation, results reported here will focus on major findings related to the originally proposed primary aims. Results bearing on secondary topics or exploratory analyses will be reserved for inclusion in future manuscripts. All relevant data are included in the tables and can be reviewed for more detailed information. 
Results are organized into two sections to highlight the study's main findings. Initially, overall results are reported for the inclusion of cultural variables within forensic psychology articles (i.e., as a whole and by article type). Results are next reported addressing limited or select inclusion of culture. As such, tables displaying results will not be reviewed in their totality when first referenced in the text. Some elements of the tables will be covered in the first section of the results, with other elements being described later. The reader will be referred back to relevant tables as needed. 


\section{CHAPTER 3.}

\section{RESULTS}

An initial sample of 480 articles was pooled from the eight selected forensic psychology journals. However, during coding an additional 18 articles were determined to meet exclusion criteria and were removed from the sample. Therefore, the final sample was comprised of 462 articles; 76 articles were classified as theoretical or review papers $(2015, n=22 ; 2016, n=24 ; 2017, n=30)$, and 386 as research articles $(2015, n=118 ; 2016, n=148 ; 2017, n=120)$. Table 2 displays the percent of theoretical/review and research articles for the entire sample, as well as within each journal. The sample as a whole had a higher proportion of research articles $(83.5 \%)$ compared to theoretical/review papers $(16.5 \%)$. Similarly, the majority of journals had higher proportions of research articles than theoretical/review publications. Notably, Behavioral Sciences and the Law and the Journal of the American Academy of Psychiatry and the Law had closer to equal representation of theoretical/review (41.7\% and 52.2\% respectively) and research articles (58.3\% and $47.8 \%$ respectively). 
Table 2

Article Type by Journal

\begin{tabular}{|c|c|c|c|c|c|c|}
\hline \multirow[b]{2}{*}{ Journal } & \multicolumn{2}{|c|}{ Total } & \multicolumn{2}{|c|}{$\begin{array}{c}\text { Theoretical/ } \\
\text { Review }\end{array}$} & \multicolumn{2}{|c|}{ Research } \\
\hline & $n$ & $\%$ & $n$ & $\%$ & $n$ & $\%$ \\
\hline Total & 462 & 100 & 76 & 16.5 & 386 & 83.5 \\
\hline Law and Human Behavior & 60 & 100 & 0 & 0 & 60 & 100 \\
\hline Behavioral Sciences and the Law & 60 & 100 & 25 & 41.7 & 35 & 58.3 \\
\hline Journal of Forensic Psychiatry and Psychology & 57 & 100 & 4 & 7.0 & 53 & 93.0 \\
\hline Psychology, Public Policy and the Law & 59 & 100 & 13 & 22.0 & 46 & 78.0 \\
\hline Criminal Justice and Behavior & 60 & 100 & 2 & 3.3 & 58 & 97.0 \\
\hline Psychology, Crime, and Law & 60 & 100 & 7 & 11.7 & 53 & 88.3 \\
\hline Legal and Criminological Psychology & 60 & 100 & 1 & 1.7 & 59 & 98.3 \\
\hline Journal of the American Academy of Psychiatry and the Law & 46 & 100 & 24 & 52.2 & 22 & 47.8 \\
\hline
\end{tabular}




\section{Cultural Inclusion in Forensic Psychology}

Table 3 provides results for all articles and for articles divided into subcategories of theoretical/review papers and research articles. Results revealed a mean of about three cultural variables incorporated into articles as a whole, with a standard deviation of 1.6 , and a range of 0 to 9 . Almost all articles (96\%) incorporated at least one cultural variable. When examined by subcategories, the vast majority of theoretical/review articles and research articles included at least one cultural variable (89.4\% and $97.2 \%$, respectively). The mean number of cultural variables present was 2.9 for both theoretical/review $(\mathrm{SD}=2.0)$ and research $(\mathrm{SD}=2.9)$ articles.

Table 3

Representation of Cultural Variable Inclusion

\begin{tabular}{lccccccc}
\hline & \multicolumn{2}{c}{ Present } & \multicolumn{2}{c}{ Not Present } & & & \\
& $n$ & $\%$ & $n$ & $\%$ & $M$ & $S D$ & Range \\
\hline Total $(\boldsymbol{N}=\mathbf{4 6 2})$ & $\mathbf{4 4 3}$ & $\mathbf{9 6 . 0}$ & $\mathbf{1 9}$ & $\mathbf{4 . 0}$ & $\mathbf{2 . 9 2}$ & $\mathbf{1 . 6}$ & $\mathbf{0 - 9}$ \\
Theoretical/Review & 68 & 89.4 & 8 & 10.5 & 2.92 & 2.0 & $0-9$ \\
$(n=76)$ & & & & & & & \\
Research $(n=386)$ & 375 & 97.2 & 11 & 2.8 & 2.91 & 1.5 & $0-9$ \\
\hline
\end{tabular}

Table 4 details rates of cultural inclusion within different sections of articles. For the total sample of articles, cultural variables had a high rate of inclusion within the introduction section (64\%). A little less than half of all articles included cultural variables within the title (34.6\%) and aims/hypotheses (42.4\%). Lower rates of inclusion were observed in the sections of articles discussing study limitations $(9.3 \%)$. Suggestions for future research efforts were coded to examine the rate at which cultural groups were included in recommendations. Those articles that suggested 
future lines of cultural research $(n=131,28.4 \%)$ most commonly suggested incorporating age/generation ( $n=50)$, gender identity $(n=48)$, and race/ethnicity $(n$ $=23$.

Table 4

Cultural Variable Inclusion Across Article Sections

\begin{tabular}{lcccccc}
\hline & \multicolumn{3}{c}{$\begin{array}{c}\text { All Articles } \\
(N=462)\end{array}$} & \multicolumn{2}{c}{$\begin{array}{c}\text { Reoretical/ } \\
(n=76)\end{array}$} & \multicolumn{2}{c}{$\begin{array}{c}\text { Research } \\
(n=386)\end{array}$} \\
\cline { 2 - 7 } \multicolumn{1}{c}{ Section } & $n$ & $\%$ & $n$ & $\%$ & $n$ & $\%$ \\
\hline Title & 160 & 34.6 & 21 & 27.6 & 139 & 36.0 \\
Introduction & 296 & 64.0 & 40 & 52.6 & 256 & 66.3 \\
Aims/Hypotheses & 196 & 42.4 & 26 & 34.2 & 170 & 44.0 \\
Multiculturally-Focused & 203 & 44.0 & 28 & 13.8 & 175 & 86.2 \\
Participant Demographics & 356 & 92.2 & ---- & ---- & 356 & 92.2 \\
Reported Results & 160 & 41.5 & --- & ---- & 160 & 41.5 \\
Study Limitations & 43 & 9.3 & 1 & 1.3 & 42 & 11.0 \\
Future Directions & 131 & 28.4 & 7 & 9.2 & 124 & 32.1 \\
\hline
\end{tabular}

Rates of inclusion for the cultural variables of interest in this study are presented in Table 5. Proceeding from left to right, Table 5 displays frequency of inclusion across articles as a whole, and then by subcategories (i.e., theoretical/review, and research). As can be seen in the table, the most commonly incorporated variables for all articles combined were age/generation (85.3\%), gender identity (82\%), and race/ethnicity (46.5\%). Almost all remaining variables were incorporated at substantially lower rates. The least included cultural variables were sexual orientation (1.7\%), religion (3.7\%), immigration (4.1\%), and language (4.5\%). Considerable differences in the inclusion of cultural variables were observed by article type. For example, when examining presence of cultural variables in any section of an article, 
theoretical/review articles had higher proportions of ability status (38.2\%) and socioeconomic status $(27.6 \%)$ compared to research articles which were $5.2 \%$ and $8.5 \%$ respectively. Additionally, the proportion of research articles including age $(89.4 \%)$, gender $(86.8 \%)$, and race/ethnicity $(50.5 \%)$ was notably higher than observed proportions for theoretical/review articles $(64.5 \%, 57.9 \%$, and $26.3 \%$ respectively).

Table 5

Rates of Inclusion by Specific Cultural Variables

\begin{tabular}{lccc}
\hline \multicolumn{1}{c}{ Cultural Variable } & $\begin{array}{c}\text { All Articles } \\
n(\%)\end{array}$ & $\begin{array}{c}\text { Theoretical/Review } \\
n(\%)\end{array}$ & $\begin{array}{c}\text { Research } \\
n(\%)\end{array}$ \\
\hline Age & $394(85.3)$ & $49(64.5)$ & $345(89.4)$ \\
Gender & $379(82.0)$ & $44(57.9)$ & $335(86.8)$ \\
Race \& Ethnicity & $215(46.5)$ & $20(26.3)$ & $195(50.5)$ \\
Indigenous Heritage & $42(9.1)$ & $2(2.6)$ & $40(10.4)$ \\
Immigration & $19(4.1)$ & $4(5.3)$ & $15(3.9)$ \\
Language & $21(4.5)$ & $5(6.6)$ & $16(4.1)$ \\
Religion & $17(3.7)$ & $6(7.9)$ & $11(2.8)$ \\
Socioeconomic Status & $54(11.7)$ & $21(27.6)$ & $33(8.5)$ \\
Employment & $42(9.1)$ & $12(15.8)$ & $30(7.8)$ \\
Education & $88(19.0)$ & $12(15.8)$ & $76(19.7)$ \\
Sexual Orientation & $8(1.7)$ & $4(5.3)$ & $4(1.0)$ \\
Neighborhood & $34(7.4)$ & $4(5.3)$ & $30(7.8)$ \\
Ability & $49(10.6)$ & $29(38.2)$ & $20(5.2)$ \\
\hline
\end{tabular}

\section{Participant Demographics}

Twenty-one research articles did not report sample demographics, as they had case-level participants (e.g., systematic review articles, probation departments as participants, etc.). Consequently, 365 research articles remained that contained descriptions of participants. The inclusion of cultural variables within reported sample descriptions for all articles and for each of the eight selected forensic psychology 
journals is presented in Table 6 . Among articles with reported sample demographics, 98\% $(n=356)$ reported at least one cultural variable in their participant descriptions. As seen in the table, the mean number of cultural variables included for this subsample was $3.1(\mathrm{SD}=1.2)$ with a range of 1 to 6 . Mean number of cultural variables included for each journal ranged from 2.5 to 3.6. Similar to results for the subsample of articles with reported sample characteristics, the vast majority of journals reported participant demographics ( $85 \%$ to $100 \%)$.

A primary aim of the study was to examine how cultural variables were conveyed within forensic psychology articles, and in particular the representation of various sociocultural identities within a cultural group. Table 7 displays their rate of inclusion in multiculturally-focused articles $(n=203)$ and within reported participant demographics $(n=356)$. Although these are different subsamples, they were included in the same table in order to draw comparisons between the rate of inclusion of distinct sociocultural identities as primary variables of interest (i.e., multiculturally-focused) and their representation in sample characteristics. These comparisons will be discussed later within the results section.

The far-right column of Table 7 details the inclusion of cultural variables in participant demographics. The data presented in bold font reflects the rate of inclusion for the specified cultural variable as a whole. The subsequent subcategories display the proportion of those articles that captured those specific sociocultural identities. Percentages within subcategories do not add up to the cumulative figures in bold as multiple sociocultural identities could be incorporated within an article and were coded to capture all subcategories included. 
Consistent with results for cultural inclusion across all articles, age (95.2\%), gender (92.4\%), and race/ethnicity (54.5\%), had the highest rates of representation within descriptions of sample demographics. All other variables had considerably lower rates of representation, although percentages across these additional variables did range fairly broadly, from education (19.1\%), and proceeding downward to indigenous heritage (11\%), socioeconomic status (7.9\%), neighborhood (7.9\%), employment (7.3\%), immigration (3.9\%), language (3.9\%), ability (3.7\%), religion $(2.8 \%)$, and sexual orientation $(0.8 \%)$.

\section{Multiculturally-focused Articles}

Out of the study sample of 462 articles, $44 \%(n=203)$ were classified as multiculturally-focused (see Table 4). Within this sample of multiculturally-focused articles, a large proportion of research articles were multiculturally-focused (86.2\%). Although almost $90 \%$ of theoretical or review articles contained at least one cultural variable, only $13.8 \%$ of articles were multiculturally-focused.

Table 7 details the inclusion of cultural variables and sociocultural identities for multiculturally-focused articles. As noted earlier, the bolded data reflects the overall rate of inclusion for a cultural variable, and the reader is directed to focus on the first two columns of the table which present the proportions of inclusion for theoretical/review and research articles. Similar to previous results age, gender, and race/ethnicity were frequently incorporated into multiculturally-focused articles for both theoretical/review $(85.7 \%, 60.7 \%$, and $32.1 \%$ respectively) and research articles $(63.4 \%, 34.3 \%$, and $10.3 \%$ respectively). 
Table 8 details the frequency of multiculturally-focused articles for the eight forensic psychology journals included in the study. For the combined or "total" category, the mean number of multiculturally-focused articles was 25 (43.9\%), and ranged from 17 (8.4\%) to 32 articles (15.8\%). Additionally, across the journals, there was marked variability in the percentage of multiculturally-focused theoretical/review articles, ranging from $0 \%$ to $47.1 \%$. Whereas, there was greater uniformity among research articles as seen in the five journals with percentages of multiculturallyfocused research articles, ranging from $86.2 \%$ to $100 \%$. The remaining three journals had approximately two-thirds $(65.6 \% \& 65.2 \%)$ to half of research articles classified as multiculturally-focused. See Table 8 for additional journal specific information. 
Table 6

Cultural Variable Inclusion within Reported Participant Demographics $(n=365)$ by Journal

\begin{tabular}{lccccc}
\hline \multicolumn{1}{c}{ Journal } & $n$ & $\%$ & $M$ & $S D$ & Range \\
\hline Total & $\mathbf{3 5 6}$ & $\mathbf{9 7 . 5}$ & $\mathbf{3 . 1}$ & $\mathbf{1 . 2}$ & $\mathbf{1 - 6}$ \\
Law and Human Behavior & 51 & 96.2 & 3.1 & 1.3 & $1-6$ \\
Behavioral Sciences and the Law & 32 & 100 & 3.3 & 1.1 & $1-6$ \\
Journal of Forensic Psychiatry and Psychology & 45 & 96.0 & 3.1 & 1.1 & $1-6$ \\
Psychology, Public Policy and the Law & 43 & 98.0 & 3.3 & 1.1 & $1-6$ \\
Criminal Justice and Behavior & 58 & 100 & 3.6 & 1.1 & $1-6$ \\
Psychology, Crime, and Law & 52 & 100 & 3.0 & 1.2 & $1-6$ \\
Legal and Criminological Psychology & 58 & 98.3 & 2.5 & 0.9 & $1-5$ \\
Journal of the American Academy of Psychiatry and the Law & 17 & 85.0 & 2.5 & 1.3 & $1-5$ \\
\hline
\end{tabular}


Table 7

Sociocultural Identity Inclusion for Multiculturally-Focused Articles $(n=203)$ and Participant Demographics $(n=356)$

\begin{tabular}{|c|c|c|c|}
\hline & $\begin{array}{l}\text { Theoretical/Review } \\
\qquad(n=28)\end{array}$ & $\begin{array}{l}\text { Research } \\
(n=175)\end{array}$ & $\begin{array}{l}\text { Participant Demographics } \\
\qquad(n=356)\end{array}$ \\
\hline Cultural Variable & $n(\%)$ & $n(\%)$ & $n(\%)$ \\
\hline Age & $24(85.7)$ & $111(63.4)$ & $339(95.2)$ \\
\hline Children (ages $0-11)$ & $13(54.2)$ & $39(35.1)$ & $35(10.3)$ \\
\hline Adolescents (ages $12-17$ ) & $16(66.7)$ & $59(53.2)$ & $67(19.8)$ \\
\hline University students & $2(8.3)$ & $2(1.8)$ & $84(24.8)$ \\
\hline Young adults (ages $18-25$ ) & $7(29.2)$ & $6(5.4)$ & $102(30.1)$ \\
\hline Adults (ages $26-64)$ & $18(75 \%)$ & $14(12.6)$ & $204(60.2)$ \\
\hline Older adults (ages 65+) & $2(8.3)$ & $9(8.1)$ & $64(18.9)$ \\
\hline Other & $0(0)$ & $0(0)$ & $9(2.6)$ \\
\hline Gender & $17(60.7)$ & $60(34.3)$ & $329(92.4)$ \\
\hline Women/Female & $9(53.0)$ & $40(66.7)$ & $225(68.4)$ \\
\hline Men/Male & $15(88.2)$ & $20(33.3)$ & $268(81.5)$ \\
\hline Transgender & $1(5.8)$ & $0(0)$ & $0(0)$ \\
\hline Race \& Ethnicity & $9(32.1)$ & $18(10.3)$ & $194(54.5)$ \\
\hline Black/African-American & $6(66.7)$ & $6(33.3)$ & $115(59.3)$ \\
\hline Latina $(\mathrm{o}) / \mathrm{Hispanic}$ & $4(44.4)$ & $2(11.1)$ & $83(42.8)$ \\
\hline White/Caucasian & $3(33.3)$ & $6(33.3)$ & $167(86.1)$ \\
\hline Asian & $1(11.1)$ & $0(0)$ & $61(31.4)$ \\
\hline Middle Eastern & $0(0)$ & $0(0)$ & $7(3.6)$ \\
\hline Pacific Islander & $0(0)$ & $0(0)$ & $12(6.1)$ \\
\hline Indian & $0(0)$ & $0(0)$ & $5(2.6)$ \\
\hline Mixed Race/Biracial & $0(0)$ & $0(0)$ & $28(14.4)$ \\
\hline Other & $3(33.3)$ & $11(61.1)$ & $105(54.1)$ \\
\hline
\end{tabular}




\begin{tabular}{|c|c|c|c|}
\hline & $\begin{array}{l}\text { Theoretical/Review } \\
\qquad(n=28)\end{array}$ & $\begin{array}{l}\text { Research } \\
(n=175) \\
\end{array}$ & $\begin{array}{l}\text { Participant Demographics } \\
(n=356)\end{array}$ \\
\hline Cultural Variable & $n(\%)$ & $n(\%)$ & $n(\%)$ \\
\hline Indigenous Heritage & $\mathbf{0}(\mathbf{0})$ & $3(1.7)$ & $39(11.0)$ \\
\hline Native American & $0(0)$ & $1(33.3)$ & $24(61.5)$ \\
\hline First Nations & $0(0)$ & $2(66.7)$ & $12(30.8)$ \\
\hline Alaskan Native & $0(0)$ & $0(0)$ & $5(12.8)$ \\
\hline Other & $0(0)$ & $0(0)$ & $3(7.7)$ \\
\hline Immigration & $4(14.3)$ & $3(1.7)$ & $14(3.9)$ \\
\hline Immigrant & $1(25.0)$ & $1(33.3)$ & $2(14.3)$ \\
\hline United States Citizen & $2(50.0)$ & $0(0)$ & $7(50.0)$ \\
\hline Other & $2(50.0)$ & $3(100)$ & $7(50.0)$ \\
\hline Language & $5(17.9)$ & $1(0.6)$ & $14(3.9)$ \\
\hline Language other than English & $1(20.0)$ & $0(0)$ & $0(0)$ \\
\hline English & $1(20.0)$ & $0(0)$ & $10(71.4)$ \\
\hline Other & $4(80.0)$ & $1(100)$ & $4(28.6)$ \\
\hline Religion & $2(7.1)$ & $6(3.4)$ & $10(2.8)$ \\
\hline Secular/Agnostic/Atheist & $0(0)$ & $0(0)$ & $3(30.0)$ \\
\hline Jewish & $1(50.0)$ & $0(0)$ & $5(50.0)$ \\
\hline Muslim & $1(50.0)$ & $1(16.7)$ & $2(20.0)$ \\
\hline Christian & $1(50.0)$ & $1(16.7)$ & $5(50.0)$ \\
\hline Other & $1(50.0)$ & $4(66.7)$ & $3(30.0)$ \\
\hline Socioeconomic Status & $9(32.1)$ & $5(2.9)$ & $28(7.9)$ \\
\hline Low SES/poverty & $5(55.6)$ & $4(80.0)$ & $8(28.6)$ \\
\hline Other & $4(44.4)$ & $1(20.0)$ & $20(71.4)$ \\
\hline Employment & $5(17.9)$ & $3(1.7)$ & $26(7.3)$ \\
\hline Unemployment & $1(20.0)$ & $0(0)$ & $9(34.6)$ \\
\hline Employment & $2(40.0)$ & $3(100)$ & $12(46.2)$ \\
\hline Other & $4(80.0)$ & $0(0)$ & $5(19.2)$ \\
\hline
\end{tabular}




\begin{tabular}{cccc}
\hline & $\begin{array}{c}\text { Theoretical/Review } \\
(n=28)\end{array}$ & $\begin{array}{c}\text { Research } \\
(n=175)\end{array}$ & $\begin{array}{c}\text { Participant Demographics } \\
(n=356)\end{array}$ \\
\cline { 2 - 4 } Cultural Variable & $n(\%)$ & $n(\%)$ & $n(\%)$ \\
\hline Education & $\mathbf{4}(\mathbf{1 4 . 3})$ & $\mathbf{5 ( 2 . 9 )}$ & $\mathbf{6 8}(\mathbf{1 9 . 1})$ \\
Grades 0-11 & $1(25.0)$ & $0(0)$ & $16(23.5)$ \\
GED or High School Diploma & $0(0)$ & $0(0)$ & $21(31.0)$ \\
Some College & $0(0)$ & $0(0)$ & $26(38.2)$ \\
Bachelor's Degree or higher & $2(50.0)$ & $0(0)$ & $32(47.0)$ \\
Other & $0(0)$ & $5(100)$ & $29(42.6)$ \\
Sexual Orientation & $\mathbf{3}(\mathbf{1 0 . 7})$ & $\mathbf{1}(\mathbf{0 . 6})$ & $\mathbf{3}(\mathbf{0 . 8})$ \\
Gay & $2(66.7)$ & $1(100)$ & $0(33.3)$ \\
Lesbian & $1(33.3)$ & $0(0)$ & $1(33.3)$ \\
Bisexual & $1(33.3)$ & $0(0)$ & $3(100)$ \\
Straight & $0(0)$ & $0(0)$ & $\mathbf{2 8}(\mathbf{7 . 9})$ \\
Neighborhood & $\mathbf{2 ( 7 . 1 )}$ & $0(0)$ & $22(78.6)$ \\
Urban/City & $1(50.0)$ & $0(0)$ & $6(21.4)$ \\
Rural & $0(0)$ & $0(0)$ & $3(10.7)$ \\
Suburb & $0(0)$ & $0(0)$ & $3(10.7)$ \\
Other & $1(50.0)$ & $0(0)$ & $\mathbf{1 3}(\mathbf{3 . 7})$ \\
Ability & $\mathbf{1 2 ( 4 2 . 9 )}$ & $\mathbf{1 3}(\mathbf{7 . 4})$ & $1(7.7)$ \\
Physical & $3(25.0)$ & $1(7.7)$ & $3(21.3)$ \\
Cognitive & $6(50.0)$ & $3(23.1)$ & $9(69.2)$ \\
Psychiatric & $7(58.3)$ & $8(61.5)$ & $0(0)$ \\
Sensory & $1(8.3)$ & $0(0)$ & $1(7.7)$ \\
Able-minded & $0(0)$ & $1(7.7)$ & \\
& & &
\end{tabular}


Table 8

Multiculturally-Focused Articles by Journal

\begin{tabular}{|c|c|c|c|c|c|c|}
\hline \multirow[b]{2}{*}{ Journal } & \multicolumn{2}{|c|}{ Total } & \multicolumn{2}{|c|}{$\begin{array}{c}\text { Theoretical/ } \\
\text { Review }\end{array}$} & \multicolumn{2}{|c|}{ Research } \\
\hline & $n$ & $\%$ & $n$ & $\%$ & $n$ & $\%$ \\
\hline Total & 203 & 43.9 & 28 & 13.8 & 175 & 86.2 \\
\hline Law and Human Behavior & 26 & 12.8 & ---- & ---- & 26 & 100 \\
\hline Behavioral Sciences and the Law & 23 & 11.3 & 8 & 34.8 & 15 & 65.2 \\
\hline Journal of Forensic Psychiatry and Psychology & 26 & 12.8 & 1 & 3.8 & 25 & 96.2 \\
\hline Psychology, Public Policy and the Law & 32 & 15.8 & 11 & 34.4 & 21 & 65.6 \\
\hline Criminal Justice and Behavior & 29 & 14.3 & 0 & 0 & 29 & 100 \\
\hline Psychology, Crime, and Law & 28 & 13.8 & 0 & 0 & 28 & 100 \\
\hline Legal and Criminological Psychology & 22 & 10.8 & 0 & 0 & 22 & 100 \\
\hline Journal of the American Academy of Psychiatry and the Law & 17 & 8.4 & 8 & 47.1 & 9 & 53.0 \\
\hline
\end{tabular}




\section{Sampling and Reported Results}

Methodological and analytic data from research articles were coded for multiculturally-focused articles. Table 9 summarizes the representation of cultural variables in the method and results sections of these articles. When cultural variables were present in the reporting of participant demographics, data was extracted from the methods and procedures for coding, in an effort to examine if the inclusion of that cultural variable reflected purposive (i.e., selected with intention) or convenience (i.e., easily accessible) sampling. The cultural variables with the highest rates of purposive sampling included, age/generation (63\%), ability status (88.9\%), language (75\%), and immigration status $(50 \%)$. Multiculturally-focused research articles $(n=175)$ were also examined to determine the extent to which cultural factors were captured within reported results. The majority of these articles included at least one cultural variable in the reporting of results $(n=160,91.4 \%)$. The most common cultural variables with reported results were age (69\%), gender $(63.1 \%)$, race/ethnicity $(26.6 \%)$, and education $(10.6 \%)$. The remaining cultural variables were included in less than $10 \%$ of multiculturally-focused research articles. See Table 9 for additional details. 
Table 9

Methodology and Data Analytic Approaches in Multiculturally-Focused Research Articles $(n=175)$

\begin{tabular}{lcccc}
\hline & \multicolumn{2}{c}{$\begin{array}{c}\text { Sampling Method } \\
(n=175)\end{array}$} & \multicolumn{2}{c}{$\begin{array}{c}\text { Results Reported } \\
(n=160)\end{array}$} \\
\cline { 2 - 5 } & Purposive & Convenience & Yes & No \\
& $n(\%)$ & $n(\%)$ & $n(\%)$ & $n(\%)$ \\
\cline { 2 - 5 } Age & $102(63.0)$ & $60(37.0)$ & $110(69.0)$ & $50(31.3)$ \\
Gender & $50(32.1)$ & $106(67.9)$ & $101(63.1)$ & $59(36.9)$ \\
Race \& Ethnicity & $9(8.6)$ & $96(91.4)$ & $41(26.6)$ & $119(74.4)$ \\
Indigenous Heritage & $2(9.5)$ & $19(90.5)$ & $5(3.1)$ & $155(96.9)$ \\
Immigration & $5(50.0)$ & $5(50.0)$ & $5(3.1)$ & $155(96.9)$ \\
Language & $6(75.0)$ & $2(25.0)$ & $2(1.3)$ & $158(98.8)$ \\
Religion & $3(42.9)$ & $4(57.1)$ & $6(3.8)$ & $154(96.3)$ \\
Socioeconomic Status & $3(15.0)$ & $17(85.0)$ & $12(7.5)$ & $148(92.5)$ \\
Employment & $0(0)$ & $12(100)$ & $9(5.6)$ & $151(94.4)$ \\
Education & $2(6.7)$ & $28(93.3)$ & $17(10.6)$ & $143(89.4)$ \\
Sexual Orientation & $0(0)$ & $2(100)$ & $1(0.6)$ & $159(99.4)$ \\
Neighborhood & $3(14.3)$ & $18(85.7)$ & $7(4.4)$ & $153(95.6)$ \\
Ability & $8(88.9)$ & $1(11.1)$ & $10(6.3)$ & $150(93.8)$ \\
\hline
\end{tabular}

\section{Limited and Selective Focus of Cultural Inclusion}

Results revealed that few cultural variables beyond age, gender, and race/ethnicity were usually included in articles. As seen in Table 5, indigenous heritage $(9.1 \%)$, employment $(9.1 \%)$, neighborhood $(7.4 \%)$, language $(4.5 \%)$, religion (3.7\%), and sexual orientation $(1.7 \%)$ were included in less than $10 \%$ of all articles within the sample. Further, results reflect a discrepancy between overall cultural inclusion and the incorporation of cultural variables as the intended focus of cultural research.

General Inclusion Versus Multiculturally-focused 
Tables 5 and 7 can be used to examine changes in representation rates of cultural variables present in any section of an article (i.e., general incorporation, Table 5) and their inclusion within multiculturally-focused articles (i.e., within the title/aims, Table 7). As observed in Table 7, the limited number of theoretical/review articles classified as multiculturally-focused $(n=28)$ artificially inflated the percentages reflecting rates of inclusion. For example, Table 5 shows the percentage of articles including language anywhere within the paper was $6.6 \%$. This rate is notably lower than the proportion of multiculturally-focused articles including language (17.9\%) as noted in Table 7, despite the same number of articles (i.e., $n=5$ ) capturing this cultural variable. Accordingly, examination of differences in proportions of cultural representation from general incorporation (i.e., Table 5) to inclusion within multiculturally-focused articles (i.e., Table 7) will be limited to the sample of research articles.

The reader is respectfully directed to focus their attention on the final column of Table 5 (i.e., general incorporation) and the second column of Table 7 (i.e., multiculturally-focused research articles). Comparisons of percentages from Table 5 to Table 7 illustrate that rates of inclusion for a number of cultural variables within multiculturally-focused articles were notably lower than their general incorporation. For example, although age was included in $89.4 \%$ of all research articles (Table 5), only $63.4 \%$ of multiculturally-focused articles (Table 7) included age as a primary cultural variable of interest. A similar decrease in proportion of representation can be seen for gender identity (general inclusion: $86.8 \%$; multiculturally-focused: $34.3 \%$ ) and indigenous heritage (general inclusion: 10.4\%; multiculturally-focused: 1.7\%). 
One stark example of change in proportions of representation can be seen in inclusion rates for race/ethnicity. When examining inclusion within any section of an article (Table 5), race/ethnicity was captured in half of all research articles. However, as seen in Table 7, only $10.3 \%$ of multiculturally-focused articles included race/ethnicity, suggesting that although race/ethnicity may be routinely included in forensic psychology articles, it is less often the focus of cultural research.

\section{Disproportionate Cultural Representation in Sample Demographics}

As seen in Table 4, less than half of research articles include cultural variables in their title (36\%) or aims/hypotheses $(44 \%)$, areas in which the primary topic of interest is typically represented. Yet, $92 \%$ of research articles included cultural variables within sample demographics, indicating that cultural identities are routinely captured within participant samples despite not being the focus of an article. Overall, examination of results revealed discrepancies between rates of cultural representation within the topic area of an article and their prevalence in participant demographics. An illustrative example highlighting this discrepancy can be seen for age within multiculturally-focused research articles (Table 7). Children (35\%) and adolescents $(53 \%)$ had relatively higher representation compared to other age groups (e.g., young adults: 5.4\%). However, only a small percentage of research participants were children $(10.3 \%)$ or adolescents $(19.8 \%)$. These results suggest that although children and adolescents may be the primary cultural group examined within a study, they are not represented at similar rates among research subjects. Similarly, adults (12.6\%), young adults (5.4\%), and university students (1.8\%) had relatively low inclusion in the 
multiculturally-focused research articles. Yet, these cultural identities had higher rates of inclusion within sample demographics $(60 \%, 30 \%$, and $24 \%$ respectively).

Other examples include gender and race/ethnicity (Table 7). Although men were the focus in only $33 \%$ of research articles, they were disproportionately represented in $81 \%$ of sample demographics. Similar disproportionate representation can be seen for a number of ethnic identities, such as Asian, Middle Eastern, Pacific Islander, Indian, and multiracial groups. No research articles incorporated these racial/ethnic identities within multiculturally-focused articles, yet they were included in the description of the demographic sample in $3 \%$ to $14 \%$ of research articles. Finally, despite a number of cultural variables noted to have relatively lower rates of inclusion in research articles, they had higher rates of representation in sample demographics. Indigenous heritage, education, employment, socioeconomic status, and neighborhood were included in less than $5 \%$ of all multiculturally-focused research articles. However, their representation in participant descriptions ranged from $7 \%$ to $19 \%$.

\section{Overrepresentation of Majority Groups}

Despite routine incorporation of some cultural variables, results indicate their inclusion primarily focuses on majority groups. For example as illustrated in Table 7, adults had higher rates of representation in participant demographics (60.2\%), compared to other age minority groups, such as older adults (18.9\%). In fact, results suggest older adults are an underrepresented cultural group within the sociocultural identity of age, as evidenced by their inclusion in less than $10 \%$ of multiculturallyfocused articles. Similarly, the majority group of White/Caucasian had higher rates of 
representation in research articles (33.3\%) and participant demographics (86.1\%).

Although Black/African-American, Latino(a)/Hispanic, and Asian were the next most represented racial/ethnic identities, the majority of other ethnic groups (i.e., Middle Eastern, Pacific Islander, Indian) had little to no inclusion.

Results revealed that even within cultural variables with lower rates of inclusion, majority groups tended to be reported at relatively higher rates compared to other minority cultural identities within the same group. Examination of reported participant demographics for the cultural variables of education and neighborhood serve as prime examples (see Table 7). As shown in the table, within education, higher education status had relatively higher representation (some college, 38.2\%; bachelor's degree or higher, 47\%) compared to lower educational attainment (less than high school education, 23.5\%). An additional example can be seen in the incorporation of neighborhood within participant demographics. Results noted higher proportions of urban/city (78.6\%) inclusion, compared to rural areas $(21.7 \%)$ and suburbs $(10.7 \%)$.

\section{Convenience Sampling}

Within multiculturally-focused articles, the rates of convenience sampling for cultural variables were examined (See Table 9). Despite being routinely included in participant demographics, study procedures reflected high rates of convenience sampling for gender identity (67.9\%) and race/ethnicity (91.4\%). Relatively higher rates of convenience sampling were observed for cultural variables with disproportionately lower representation in sample characteristics, including: education level (93\%), indigenous heritage (90\%), socioeconomic status $(85 \%)$, and neighborhood (85\%). Similarly, sexual orientation and employment within sample 
demographics reflected convenience sampling in $100 \%$ of those research articles, likely due to their minimal inclusion within research articles ( $n=3$ and $n=12$, respectively).

Minimal Cultural Inclusion in Study Limitations and Future Directions

For research articles that did not incorporate culture in major sections of the publication, data was extracted from the discussion section of the article to determine if this was acknowledged as a study limitation. Multiculturally-focused research articles were excluded from this analysis as they already captured culture in their articles $(n=175)$. Of the 211 research articles that did not incorporate culture in depth, most did not mention the lack of cultural inclusion as a study limitation $(n=$ $169,80.1 \%)$. All research articles $(n=386)$ were coded to examine if suggestions for future research endeavors included cultural groups: the vast majority ( $n=331,71.6 \%)$ did not. 


\section{CHAPTER 4.}

\section{DISCUSSION}

The present study is the first to examine the incorporation of culture within forensic psychology research, utilizing a thorough and extensive list of cultural identities and groups. This study sought to examine the prevalence of cultural variables and varying approaches to their inclusion within forensic psychology research. Further, this study extends previous work by not only identifying the proportion of multiculturally-focused research articles in major forensic psychology journals, but also by examining methodological and data analytic techniques used in cultural research within the field. The primary aims of this study served a broader purpose, which was to create an opportunity to reflect on strengths within the field, as well as to highlight areas for growth and continued development.

\section{Strengths within Forensic Psychology}

The vast majority of articles (96\%) within the sample included at least one cultural variable. Cultural variables were more prevalent in the introduction section of publications where content generally focuses on reviewing existing literature, covering pertinent information from other data sources (e.g., census data), and summarizing past research findings. Results indicate that cultural variables appear most often within descriptions of study samples, with such descriptions referencing at least one cultural variable $98 \%$ of the time.

The inclusion rate for cultural variables within sample demographics in the current study appears to represent an increase compared to findings of previous studies. For example, Carter and Forsyth (2007) found that only $43 \%$ of articles in 
their sample identified the race/ethnicity of participants, compared to $54.5 \%$ in the present study. Furthermore, in the present study, almost half of all articles were classified as multiculturally-focused. Previous research has examined the extent to which culture, specifically race/ethnicity, has been examined in-depth within forensic psychology research and found lower rates than the current study. Padilla and colleagues (2008) found Hispanics were only discussed as the variable of interest in $5.6 \%$ of articles, compared to rates of $44 \%$ across theoretical/conceptual articles and $11 \%$ across research studies in the present study. Comparing the results of previous research to the current study reflect improvement in the incorporation of cultural variables within forensic psychology research. Additionally, across the entire sample of articles in the current study, a mean of three cultural groups were included per publication, indicating higher rates of cultural inclusion will likely be obtained when culture is examined from a broader lens using a more extensive list of cultural groups. Altogether, these results reflect notable progress toward increased inclusion of culture within forensic psychology research.

Finally, the current study found a trend suggesting high rates of inclusion for certain cultural variables. The most prevalent cultural variables in forensic psychology articles were age/generation, gender identity, and race/ethnicity. These variables were commonly included in both types of articles and their incorporation could be seen throughout various sections of articles, from the title and aims to suggestions for future lines of research. Such cultural variables as age, gender, and racial/ethnic minority groups have important impact within forensic psychology. For example, extensive research shows Black American adults are incarcerated at significantly 
higher rates than White Americans (Bobo \& Thompson, 2006) and are disproportionately more likely to received harsher punishments, such as the death penalty (Baldus, Woodworth, Zuckerman, Weiner, \& Brofitt, 1998). Moreover, Black adolescent offenders who are transferred to adult court for trial and sentencing, receive significantly more punitive sentences than their White counterparts (Eberhardt, Davies, Purdie-Vaughns, \& Johnson, 2006). Additionally, gender identity groups such as transgender individuals, face unique challenges and discrimination within the criminal justice and legal systems (James et al., 2016). Transgender women, especially women of color, frequently report being profiled by police as suspected sex workers (“walking while transgender;” Ritchie, 2017). Additionally, transgender and nonbinary individuals also may be housed in shelters or correctional facilities that do not match their gender identities, leaving them vulnerable to assault (Spade, 2006).

Rates of purposive sampling found in the current study may help explain higher rates of cultural inclusion for some variables. For example, age/generation was one of the most frequently incorporated cultural variables and when included in participant samples, had one of the highest rates of purposive selection. Similarly, the cultural variable of ability status $(88.9 \%)$ had relatively high rates of purposive sampling compared to other cultural variables included in sample demographics. This is a promising finding given literature highlighting the relevance of these cultural groups within psychology and law. Individuals with serious mental illness are classified as having a psychiatric disability and are overrepresented in the U.S. criminal justice system (Prins, 2014). Further, their contact with the criminal justice systems can intensify social marginalization and fuel stigmatization, exacerbating 
chronic incapacitation well beyond the effects of mental illness (Drucker, 2011; Prins, 2014).

A final example of the effects of purposive sampling can be seen for the cultural variable of language. Notably in the current study, language (4.5\%) was one of the least incorporated cultural variables, yet it had one of the highest rates of purposive sampling (75\%). Language considerations are critical within the criminal justice system as barriers to accessing resources in a native language have serious consequences, especially for offenders with mental health problems (Gomez-Duran \& Jones, 2018; Antonius \& Martin, 2015; Davis, Erez, \& Avitabile, 1998). For example, some research indicates that foreign born offenders are more likely to be remanded in custody while awaiting trail and more likely to be sentenced to terms of imprisonment after convictions compared to other offenders (European Committee on Crime Problems, 2012). These results provide evidence that researchers' inclusion of cultural variables in articles can reflect their overall or primary study objectives, rather than occurring by mere happenstance.

Overall, the routine inclusion of these cultural variables, such as age and gender identity, may be due to increased awareness of the prevalence and relevance of specific cultural groups prominent in forensic psychology. The frequent and growing inclusion of these cultural variables is a hopeful sign that other important cultural variables will also be included more often in future research. Further, a notable proportion of forensic psychology articles incorporated culture, thereby suggesting growth in research addressing culture over the past few decades. Given the centrality of cultural factors in the psychology-law interface, such promising results and trends 
bode well for the field. These positive outcomes serve to reinforce efforts to further advance the quality and quantity of forensic psychology cultural research.

\section{Areas for Growth}

Positive trends and growth were not uniform, with other results highlighting areas needing greater attention. A number of cultural groups with important implications for the field had little to no inclusion in forensic psychology articles. For example, immigration status was one of the least incorporated cultural variables, with inclusion in less than 5\% of all articles. In contrast, estimates suggest there are 11 million undocumented foreign residents, representing approximately $3.3 \%$ of the U.S. population (Pew Research Center, 2019). A U.S. Department of Justice report (2019) found that over the past 20 years, there has been exponential growth in the representation of non-U.S. citizens in the federal criminal justice system due to changes in immigration policing and policy. In 1998, 63\% of all federal arrests were of U.S. citizens, however by $2018,64 \%$ of all federal arrests were of non-U.S. citizens. Ninety-five percent of the increase in federal arrests across this 20 year span was due to immigration offenses (Motivans, 2019). According to the American Civil Liberties Union (2019), over the last several years, the use of detention as an immigration enforcement strategy has increased exponentially, with many immigrants detained, within correctional-like facilities, for prolonged periods of time which is known to have serious negative consequences for mental health functioning.

Moreover, the American Psychological Association (APA) has indicated that factors such as the stress of migration, trauma experienced in their native countries, and discrimination or language barriers, make U.S. immigrants more likely to suffer from 
mental illness than U.S.-born individuals (APA, 2002). It is safe to assume this group of individuals would have unique mental health treatment needs (e.g., trauma) that may not be addressed through routine rehabilitation treatment typically offered within correctional facilities (e.g., substance abuse treatment, anger management, etc.)

Similarly, sexual orientation status was rarely included in studies despite a growing body of literature suggesting that sexual minority status can have serious consequences in the legal system. For example, studies indicate that LGBTQ youth, particularly LGBTQ youth of color, are overrepresented in the U.S. juvenile justice system and are subjected to harsh and inequitable conditions of confinement (Center for American Progress \& Movement Advancement Project, 2016; Hunt \& MoodieMills 2012; Irvine \& Canfield 2016). There is evidence that LBGTQ youth are also more likely than heterosexual youth to report having been detained for offenses commonly associated with survival strategies, such as running away, truancy, technical violations, or prostitution (Irvine 2010; Garnette, Irvine, Reyes, \& Wilber 2011). Additionally, LGBTQ youth often have unmet social service needs, mental health symptoms, and past trauma, which have been found to be associated with increased contact, as well as length of involvement, with the juvenile justice system (Maschi, Hatcher, Schwalbe, \& Rosato 2008).

The current study also found differences in rates of inclusion by type of article, suggesting that some cultural variables may be viewed as more relevant in certain areas of scholarly works than in other areas. More specifically, only a small percentage of theoretical or review papers were classified as multiculturally-focused. Additionally, findings suggest that cultural variables such as ability status and 
socioeconomic status had notably higher rates of inclusion in theoretical and review articles than in research articles. Conversely, research articles were more likely to include age, gender, and race/ethnicity compared to theoretical or review articles. Inclusion of cultural variables in both types of articles is critical for the advancement of cultural research in forensic psychology. Theoretical or conceptual articles generally reference abstract principles rooted in science, in order to develop a new theory or framework, or to explore theories in innovative ways. Review articles synthesize original research and scholarly literature relevant to a topic area. Both theoretical and review articles typically evaluate the state of research and/or suggest topics for future research that may address gaps in knowledge. Moreover, both rely on original research designed to contribute to scientific knowledge. Given that both types of articles can influence the focus of future research, increased efforts to incorporate cultural variables across both types of articles more extensively would likely make important contributions to scientific progress.

A notable area for growth is increased efforts to incorporate cultural variables as the primary focus of academic scholarship. The current study found relatively low rates of cultural inclusion within sections of articles addressing the intended topic or area of interest. Specifically, about one-third of articles included a cultural variable in the title or aims/hypotheses, a frequency considerably lower than the rate found when examining any section of an article. This differential frequency is due to the high rates with which cultural variables were included when reporting participant demographics. The disproportionate inclusion of cultural variables within sample descriptions, compared to multiculturally-focused articles, suggests their incorporation was not the 
primary purpose of an article. Instead, the frequent presence of some cultural variables in participant demographics may reflect an expectation for their inclusion as part of a routine practice for reporting sample diversity. For example, Law and Human Behavior instructs researchers in its submission guidelines to report the age, gender, ethnicity, immigration history, SES and any other relevant demographic factors within the methods section of the manuscript. This directive may reflect an attempt to encourage researchers to address the importance of diverse participant samples for generalizable results. However, as seen in the results of the current study, this standard approach to reporting cultural variables in sample demographics may have an unintended effect of relegating culture to the methods section of an article and has not yet translated to the incorporation of culture as the primary variable of interest.

Further, the current study found high rates of convenience sampling for most cultural variables included in sample demographics. Similarly, results indicate a notable discrepancy between the cultural group identified as the primary focus of the study (i.e., captured in the title or hypotheses) and their representation in sample demographics. For example, even when children and adolescents were described as the intended focus, the respective studies often had lower rates of inclusion in participant samples compared to other sociocultural identities within age, such as adults or university students. Altogether, results such as these suggest that higher rates of cultural inclusion may be due to convenient access to this cultural data, rather than an intentional focus on a cultural group.

Another important area of growth is research addressing the overrepresentation of majority groups within cultural variables frequently incorporated into articles. 
Results showed that for many cultural groups the inclusion of minority group members was lower than majority groups. Examples include the observed higher rates of inclusion for adults compared to older adults, for men and women with almost no articles including other gender identities (e.g., transgender, gender non-conforming, non-binary), and for White rather than other racial/ethnic or indigenous heritage minority groups such as Native populations. Although the incorporation of cultural variables in general is critical for forensic psychology research, the beliefs, attitudes, and values that would influence or interact with outcomes of interest in the field, are inherent in minority cultural groups.

Finally, an additional area of need is to increase the incorporation of cultural variables in the discussion section of articles. Most articles in the current study did not include cultural variables when addressing limitations or suggesting lines of future research. The relative dearth of attention to cultural variables in these areas is concerning for multiple reasons. When articles address study limitations, acknowledging culture and diversity speaks to the importance of its inclusion within research. The absence or limited inclusion of cultural variables may be related to feasibility issues, which if highlighted could have important implications for the field. Detailing difficulties accessing multicultural populations or limited availability of data sources for cultural variables would be informative and could facilitate efforts to develop and implement approaches that could aid and assist future cultural research endeavors. Related to recommendations for future research, discussion of cultural groups for future inclusion is a critical opportunity to contribute to efforts aimed at 
improving cultural research. These suggestions would likely have a positive impact on generating ideas and thereby increasing cultural research within forensic psychology.

\section{Study Limitations}

Although the present study adds to the body of literature examining cultural research in forensic psychology, study limitations need to be taken into account. First, though efforts were made to comprise a multicultural research team, there was little diversity in visible cultural identities for team members. Future research would benefit from larger, more diverse research teams in an effort to be more culturally representative, increase inclusion of multicultural knowledge and perceptions, and facilitate coding more exhaustive samples of research articles. Second, the present study did not use tests of statistical significance within data analyses. Future research employing such analytic techniques would increase confidence that generated results were not due to chance and would provide quantitative values (e.g., $p$ values or effect sizes) that could speak to the magnitude of differences between observed frequencies for cultural variables.

Another study limitation was the selective focus on prevalence rates for cultural variables in research studies, without coding the quality of cultural inclusion. Carter and Forsyth (2007) employed a classification system designed to capture the quality of cultural inclusion (e.g., cultural-deprivation vs. race-based) in articles. Additionally, the present study did not examine intersectionality of cultural identities within articles. This level of in-depth assessment was not feasible for the current study given such factors as limitations in resources and the need to restrict the scope of the undertaking. However, future research aimed at examining the quality of cultural 
research for a diverse list of intersecting cultural groups would be an important contribution.

\section{Potential Implications}

Despite these limitations, study outcomes have important potential implications for improving the incorporation of culture within forensic psychology research. Notably, the current study underscores the critical need for intentional inclusion of culture in order to promote the generation of cultural research within the field. It can be highly beneficial to make intentional decisions at the outset of designing a research study or when considering the purpose of an article. Psychological research seeks to describe, explain, or predict psychological phenomena through implementation of the scientific method, in an effort to approximate truth as closely as possible. Such efforts are often intended with the ultimate goal of utilizing enhanced knowledge to create evidence based strategies or approaches that solve problems and in turn, improves lives (Cacioppo et al., 2004; van der Vijver \& Matsumoto, 2010).

Many posit that it is impossible to understand psychological processes and phenomena without considering the cultural backgrounds and influences in which they are embedded (Grossman \& Ng, 2013; Shweder \& Borne, 1984). Such a viewpoint speaks to the notion that good cultural research is good science. In psychology, good science is produced by competent research methodology that aligns with the scientific method and delineates specific steps followed in the research protocol. One of those critical steps is creating a clear definition for a variable or topic of interest, as it supports strong methodology and ensures the reproducibility of the results (Cacioppo 
et al., 2004). Therefore, quality cultural research is that which explicitly details the psychological reflection of culture that is believed to be shaping an observed outcome of interest, in order to establish metric equivalence, and to link it to the outcome in question (van der Vijver \& Matsumoto, 2010; Lonner \& Adamopoloous, 1997). When done correctly, this process will more clearly elucidate and identify the specific aspects and facets of culture at play (van der Vijver \& Matsumoto, 2010). Drifting from sound cultural methodology can have serious impact on the quality of cultural research.

One such impacted area is the way culture is commonly defined within forensic psychology research. In the majority of psychological research including cultural variables, individual axes of identity (e.g., race, gender, class, sexuality) are investigated and sociocultural categorical groupings (e.g., natural born vs. immigrant, middle class vs. impoverished) are created. Traditionally in quantitative research this is done through the use of demographic variables (Hancock, 2007; Helms et al., 2005; Rouhani, 2014). As evidenced in the current study, culture is predominantly captured within sample demographics.

However, demographic data collection is typically not theoretically based. Instead the vast majority of research collects data for demographic variables using conceptualizations based on government census data (Hancock, 2007). Census data are intended to count and quantify representation in various sociocultural groups. When census data are reported, it is strictly relegated to reporting frequencies and percentages meant to place sociocultural groups in nominal, ordinal, or frequency order (APA, 2017). Census data were not designed for the purposes of examining, 
understanding, or inferring complex inner cultural workings. Accordingly, the aim was not to create items or variables that would capture, reflect, or incorporate meaningful cultural facets or aspects. The concern is that this approach can result in researchers using the concept of culture (i.e., sociodemographic groups) within their research rather than studying cultural aspects or dynamics (James, 2001). This is especially important for studies aimed at studying and understanding culture. When demographic variables are used as proxies for culture, it suggests that single categories provide broad or even all-encompassing explanations for relationships between culture and a psychological construct. This approach can limit our understanding human behavior and impedes efforts that help elucidate the complex ways in which individuals experience life (James, 2001; McCall, 2005).

Moving toward studying culture from a dynamic viewpoint is critical for the field as other disciplines within psychology have made concerted efforts to advance the state of cultural research. For example, other areas of psychological research such as feminist, counseling, and cultural psychology have called for cultural research to move away from using sociocultural demographic variables to study culture (Helms, Jernigan, Mascher, 2005; Hancock, 2007; Smedley \& Smedley, 2005). These fields have cited the critical need to instead use cultural constructs (e.g., perceived oppression; racial/ethnic identity) and to increase the use of intersectional research methods and analytic approaches (Hancock, 2007; James, 2001). They posit that concepts related to cultural values, customs, beliefs, and attitudes have more inherent meaning than categorical labels used for sociocultural groups (Helms et al., 2005; Phinney, 1996). This approach calls for shifting away from using categories as 
independent variables, towards identifying the underlying concepts related to these cultural groups. Cultural constructs could be identity attitudes, levels of racism, gender roles, stereotype threat, or perceived discrimination.

Additionally, across all disciplines, psychologists are encouraged to consider the intersecting cultural contexts that contribute to an individual's diverse identities (APA, 2017). Intersectionality incorporates the multiple contexts - cultural, structural, sociobiological, economic, and social - that shape individuals. For many individuals, the social groups they belong to have inherent structural inequalities, resulting in marginalized identities that experience oppression, prejudice, and discrimination (APA, 2017; Crenshaw, 1991). Conversely, cultural identities also have majority groups within social categories that will afford experiences of privilege (e.g., White men). Intersectionality as an approach aims to capture the extensive within-in group differences in identities that can be found in both majority and minority group members, and argues the importance of considering the multiple, interacting and intersecting social and cultural identities within a single individual. Generating cultural research from the framework of intersectionality can advance the state of research within forensic psychology and elucidate the role and influence of culture on key concepts related to psychology and law.

There is a unique opportunity for the field to consider the above implications to increase the quantity and quality of cultural research within forensic psychology. Intentional decisions to include cultural groups and constructs as the primary interest of an article will increase the prevalence of cultural research significantly. Further, incorporation of culture throughout an article signifies the importance of these cultural 
topics and may create a long-standing trend to routinely address multicultural considerations. Such efforts would likely enhance the quality of cultural research from mere minimal inclusion toward in-depth examination.

\section{Practical Applications and Future Directions}

The findings of the current study highlight a number of practical applications that could facilitate the continued growth of cultural research in forensic psychology. For example, specialty journals in psychology and law could develop diversity statements or address the importance of multicultural considerations within their mission statements. Similarly, forensic psychology journals could create submission guidelines requesting researchers write a brief statement detailing their inclusion of diversity, or acknowledgement of limited cultural inclusion, within a manuscript. Additionally, addressing principles of cultural research within guidelines for manuscript submissions could communicate to interested authors the importance of cultural inclusion within research submissions. For example, members of the editorial board for Law and Human Behavior published an article within the journal addressing initiatives to expand diversity within the journal's publications (McAuliff et al., 2019). They noted their intention was to "encourage greater and more thoughtful consideration of diversity in our field and to be clear that [they] welcome submissions addressing diverse populations and diversity-related issues at Law and Human Behavior." Such statements reflect appreciation for the importance of cultural research and dedication to publishing culturally relevant manuscripts.

A number of practical tools or aides could also be developed to increase incorporation of culture within forensic psychology research. For example, checklist- 
like forms could be designed to increase addressing or incorporating culture from the outset of designing a study or establishing the purpose of an article. This could be done by simply posing questions aimed at increasing cultural considerations with the goal of facilitating rationales behind the inclusion or exclusion of cultural variables for a proposed topic of an article. These checklists could also be used to help researchers identify ways in which culture can be included throughout an article. Item checklists could include, for example, a reminder to provide summaries of relevant scientific research for various cultural groups in the introduction section, and to address limitations or future direction of research for cultural aspects within the discussion section.

Finally, study results provide a foundation to advocate for future research examining the status, and one hopes, continued improvement of cultural research in forensic psychology. For example, surveying forensic psychology scholars on their beliefs or attitudes on the inclusion of cultural variables in research could illuminate areas of strength or uncover common problematic approaches. Additionally, assessing understanding of cultural research methodology could highlight areas in which increased awareness or training may prove particularly beneficial for improving cultural research competency. Further, results of this study support future research efforts aimed at identifying and remedying barriers to cultural inclusion within forensic psychology. Such research endeavors would result in a better understanding of what does or does not work to increase the representation of cultural groups and examination of cultural constructs within the field. 


\section{CONCLUSION}

It is hoped the present study serves as a call to action for the field of forensic psychology. The current findings have identified a number of areas for improvement of cultural research within forensic psychology; mainly, that the field needs to better incorporate culture into all aspects of its research. Identifying potential areas for improvement should not be viewed as a negative agenda. Rather, it is meant to invigorate researchers, and to highlight the importance of focusing significant efforts and energy into contributing sound cultural methodological research within forensic psychology. This study generated both positive outcomes but also areas of concern, and it is hoped that in particular, identifying areas requiring attention will challenge the field to grow, adapt, and develop in its approach to conducting cultural research. When the population we serve is predominantly diverse, our research must reflect that diversity in the groups studied, the methods implemented, the analyses utilized, and the future generation of culturally-driven research questions. 


\section{APPENDICES}

\section{APPENDIX A}

Coding Sheet for Articles

\section{Coding Sheet}

\begin{tabular}{ll} 
Coder Name & \multicolumn{1}{c}{ Date } \\
\hline Tracking Information & \\
Journal and Article Information & $\square$ Behavioral Sciences \& the Law \\
$\square$ Law \& Human Behavior & $\square$ Psychology, Public Policy, \& the Law \\
$\square$ Journal of Forensic Psychiatry \& & $\square$ Psychology, Crime, \& Law \\
Psychology & $\square$ Journal of the American Academy of \\
$\square$ Criminal Justice \& Behavior & Psychiatry \& the Law \\
$\square$ Legal \& Criminological Psychology & \\
& \\
Title of & \\
Article & \\
Volume & \\
Type of Article & \\
$\square$ Theoretical/conceptual & \\
$\square$ Research & $\square$ Meta-analysis \\
$\square$ Systematic review & $\square$ Systematic review \& Meta-analysis \\
$\square$ Unable to determine & \\
$\square$ Other (Explain) &
\end{tabular}

Is this article conducted in an international country or is it addressing/discussing topics related to or present in other countries? (If yes, code in the "International" section)

$\square$ Yes

No

Unable to Determine

Other/NA/Explain 


\section{Theoretical/Conceptual or Review Articles}

1) Were cultural variables included in the title of the article?

$\square$ Yes $\quad \square$ Unable to Determine

$\square$ No $\quad \square$ Other/NA/Explain

2) Were cultural factors present in the literature review/introduction?

$\square$ Yes $\quad \square$ Unable to Determine

$\square$ No $\quad \square$ Other/NA/Explain

3) Were cultural factors present in the aims/purpose of the study?

$\square$ Yes

$\square$ Unable to Determine

$\square$ No $\quad \square$ Other/NA/Explain

4) Please check all of the cultural variables included/described/reported in the ENTIRE article?

$\square$ Age/Generation

$\square$ Children (11 \& Under) $\mid \square$ Adolescents (12-17) | $\square$ College Students

$\square$ Young Adults (18-25) | $\square$ Adults | $\square$ Older Adults/Elderly (65+)

$\square$ Unable to Determine

$\square$ Description:

$\square$ Gender

$\square$ Men | $\square$ Women | $\square$ Non-Binary/Fluid | $\square$ Trans

$\square$ Genderqueer | $\square$ Cisgender

$\square$ Unable to Determine

$\square$ Description:

$\square$ Race \& Ethnicity

$\square$ Black | $\square$ Latina(a)/Hispanic | $\square$ White | $\square$ Asian | $\square$ African

$\square$ Middle Eastern | $\square$ Pacific Islander | $\square$ Indian | $\square$ Mixed Race

$\square$ Biracial | $\square$ Other

$\square$ Unable to Determine

$\square$ Description:

$\square$ Indigenous Heritage

$\square$ Native American | $\square$ First Nations | $\square$ Alaskan Native

$\square$ Inuit | $\square$ Native Hawaiians

$\square$ Unable to Determine

$\square$ Description: 
$\square$ Immigration

$\square$ Immigrant | $\square$ Us-born | $\square$ Refugee | $\square$ International students

$\square$ Undocumented Immigrants | $\square$ US Citizens

$\square$ Unable to Determine

$\square$ Description:

$\square$ Language

$\square$ English | $\square$ English Second Language | $\square$ Multilingual | $\square$ Other

$\square$ Unable to Determine

$\square$ Description:

$\square$ Religion/Spirituality

$\square$ Christian | $\square$ Secular/Agnostic/Atheist | $\square$ Jewish

$\square$ Muslim | $\square$ Hindu | $\square$ Buddhist

$\square$ Unable to Determine

$\square$ Description:

$\square$ Income/SES

$\square$ Description:

$\square$ Employment

$\square$ Description:

$\square$ Education

$\square$ 0-11(some HS) | $\square$ GED | $\square$ High School Diploma | $\square$ Beyond High School

$\square$ Associate's Degree | $\square$ Some College | $\square$ Bachelor's Degree

$\square$ Master's Degree $\mid \square$ Graduate Degree

$\square$ Unable to Determine

$\square$ Description:

$\square$ Sexual Orientation

$\square$ Straight | $\square$ Gay | $\square$ Lesbian | $\square$ Bisexual | $\square$ Pansexual | $\square$ Asexual

$\square$ Queer | $\square$ Questioning

$\square$ Unable to Determine

$\square$ Description:

$\square$ Neighborhood

$\square$ Urban/City | $\square$ Rural | $\square$ Suburb | $\square$ Inner-city

$\square$ Unable to Determine

$\square$ Description:

$\square$ Ability/Disability

$\square$ Able-bodied | $\square$ Able-minded | $\square$ Physical | $\square$ Cognitive

$\square$ Sensory | $\square$ Psychiatric

$\square$ Unable to Determine

$\square$ Description:

$\square$ None

$\square$ Unable to determine 


\section{MULTICULTURALLY-FOCUSED STUDY}

5) Does this article meet the criteria of being multiculturally-focused?

$\square$ Yes - Cultural variables are mentioned in the title, introduction, and/or purpose sections

$\square$ No

$\square$ Unable to determine

DISCUSSION/CONCLUSION/LIMITATIONS

6) If culture was not considered in this study, was this acknowledged as a limitation?

(If culture was considered, highlight NA)

$\square$ Yes $\quad \square$ Unable to Determine

$\square$ No $\quad \square$ Not Applicable

7) Were future lines of cultural research suggested?

$\square$ Yes $\square$ No

$\square$ Unable to Determine $\quad \square$ Group not specified

$\square$ Age/Generation

$\square$ Gender

$\square$ Race \& Ethnicity

$\square$ Religion/Spirituality

$\square$ Income/SES

$\square$ Employment

$\square$ Education

$\square$ Sexual Orientation

$\square$ Indig Heritage

$\square$ Immigration

$\square$ Neighborhood

$\square$ Language

$\square$ Ability/Disability

\section{FORENSIC PSYCHOLOGY FOCUS AREA}

8) Please type in the keywords listed under the title/abstract of the article

$\square$ Keywords

$\square$ No Keywords listed 


\section{Research \& Meta-analysis Articles}

1) Were cultural variables included in the title of the article?
$\square$ Yes
$\square$ Unable to Determine

$\square$ No

$\square$ Other/NA/Explain

2) Were cultural factors present in the literature review/introduction?
$\square$ Yes
$\square$ Unable to Determine
$\square$ No
$\square$ Other/NA/Explain

3) Were cultural factors present in the hypotheses/aims/purpose of the study?

$\square$ Yes

$\square$ Unable to Determine

$\square$ No

$\square$ Other/NA/Explain

4) Please check all of the cultural variables included, described, or highlighted in the title and/or hypotheses/aims of the article

$\square$ Age/Generation

$\square$ Children (11 \& Under) $\mid \square$ Adolescents (12-17) | $\square$ College Students

$\square$ Young Adults (18-25) | $\square$ Adults | $\square$ Older Adults/Elderly (65+)

$\square$ Unable to Determine

$\square$ Description:

$\square$ Gender

$\square$ Men | $\square$ Women | $\square$ Non-Binary/Fluid | $\square$ Trans

$\square$ Genderqueer | $\square$ Cisgender

$\square$ Unable to Determine

$\square$ Description:

Race \& Ethnicity

$\square$ Black | $\square$ Latina(a)/Hispanic | $\square$ White | $\square$ Asian | $\square$ African

$\square$ Middle Eastern | $\square$ Pacific Islander | $\square$ Indian | $\square$ Mixed Race

$\square$ Biracial | $\square$ Other

$\square$ Unable to Determine

$\square$ Description:

$\square$ Indigenous Heritage

$\square$ Native American | $\square$ First Nations | $\square$ Alaskan Native

$\square$ Inuit | $\square$ Native Hawaiians

$\square$ Unable to Determine

$\square$ Description:

$\square$ Immigration

$\square$ Immigrant | $\square$ Us-born | $\square$ Refugee | $\square$ International students

$\square$ Undocumented Immigrants | $\square$ US Citizens

$\square$ Unable to Determine

$\square$ Description: 
$\square$ Language

$\square$ English | $\square$ English Second Language | $\square$ Multilingual | $\square$ Other

$\square$ Unable to Determine

$\square$ Description:

$\square$ Religion/Spirituality

$\square$ Christian | $\square$ Secular/Agnostic/Atheist | $\square$ Jewish

$\square$ Muslim | $\square$ Hindu | $\square$ Buddhist

$\square$ Unable to Determine

$\square$ Description:

$\square$ Income/SES

$\square$ Description:

$\square$ Employment

$\square$ Description:

$\square$ Education

$\square$ 0-11(some HS) | $\square$ GED | $\square$ High School Diploma | $\square$ Beyond High School

$\square$ Associate's Degree | $\square$ Some College | $\square$ Bachelor's Degree

$\square$ Master's Degree $\mid \square$ Graduate Degree

$\square$ Unable to Determine

$\square$ Description:

$\square$ Sexual Orientation

$\square$ Straight | $\square$ Gay | $\square$ Lesbian | $\square$ Bisexual | $\square$ Pansexual | $\square$ Asexual

$\square$ Queer | $\square$ Questioning

$\square$ Unable to Determine

$\square$ Description:

$\square$ Neighborhood

$\square$ Urban/City | $\square$ Rural | $\square$ Suburb | $\square$ Inner-city

$\square$ Unable to Determine

$\square$ Description:

$\square$ Ability/Disability

$\square$ Able-bodied | $\square$ Able-minded | $\square$ Physical | $\square$ Cognitive

$\square$ Sensory | $\square$ Psychiatric

$\square$ Unable to Determine

$\square$ Description:

$\square$ None

$\square$ Unable to determine 


\section{PARTICIPANTS}

5) Does the article describe the demographic makeup of the sample(s)? (If "no", skip to \#7)

$\begin{array}{ll}\square \text { Yes } & \square \text { Unable to Determine } \\ \square \text { No } & \square \text { Not Applicable }\end{array}$

6) Please check all of the cultural variables used to describe the study participants?

$\square$ Age/Generation

$\square$ Children (11 \& Under) $\mid \square$ Adolescents (12-17) | $\square$ College Students

$\square$ Young Adults (18-25) | $\square$ Adults | $\square$ Older Adults/Elderly (65+)

$\square$ Unable to Determine

$\square$ Description:

$\square$ Gender

$\square$ Men | $\square$ Women | $\square$ Non-Binary/Fluid | $\square$ Trans

$\square$ Genderqueer | $\square$ Cisgender

$\square$ Unable to Determine

$\square$ Description:

Race \& Ethnicity

$\square$ Black | $\square$ Latina(a)/Hispanic | $\square$ White | $\square$ Asian | $\square$ African

$\square$ Middle Eastern | $\square$ Pacific Islander | $\square$ Indian | $\square$ Mixed Race

$\square$ Biracial | $\square$ Other

$\square$ Unable to Determine

$\square$ Description:

$\square$ Indigenous Heritage

$\square$ Native American | $\square$ First Nations | $\square$ Alaskan Native

$\square$ Inuit | $\square$ Native Hawaiians

$\square$ Unable to Determine

$\square$ Description:

$\square$ Immigration

$\square$ Immigrant | $\square$ Us-born | $\square$ Refugee | $\square$ International students

$\square$ Undocumented Immigrants | $\square$ US Citizens

$\square$ Unable to Determine

$\square$ Description:

$\square$ Language

$\square$ English | $\square$ English Second Language | $\square$ Multilingual | $\square$ Other

$\square$ Unable to Determine

$\square$ Description:

$\square$ Religion/Spirituality

$\square$ Christian | $\square$ Secular/Agnostic/Atheist | $\square$ Jewish

$\square$ Muslim | $\square$ Hindu $\mid \square$ Buddhist

$\square$ Unable to Determine

$\square$ Description: 
$\square$ Income/SES

$\square$ Description:

$\square$ Employment

$\square$ Description:

$\square$ Education

$\square$ 0-11(some HS) | $\square$ GED | $\square$ High School Diploma | $\square$ Beyond High School

$\square$ Associate's Degree | $\square$ Some College | $\square$ Bachelor's Degree

$\square$ Master's Degree $\mid \square$ Graduate Degree

$\square$ Unable to Determine

$\square$ Description:

$\square$ Sexual Orientation

$\square$ Straight | $\square$ Gay | $\square$ Lesbian | $\square$ Bisexual | $\square$ Pansexual | $\square$ Asexual

$\square$ Queer | $\square$ Questioning

$\square$ Unable to Determine

$\square$ Description:

$\square$ Neighborhood

$\square$ Urban/City | $\square$ Rural | $\square$ Suburb | $\square$ Inner-city

$\square$ Unable to Determine

$\square$ Description:

$\square$ Ability/Disability

$\square$ Able-bodied | $\square$ Able-minded | $\square$ Physical | $\square$ Cognitive

$\square$ Sensory | $\square$ Psychiatric

$\square$ Unable to Determine

$\square$ Description:

$\square$ None

$\square$ Unable to determine 
7) Does this article meet the criteria of being multiculturally-focused? (If "no", skip to \#14)

$\square$ Yes - Cultural variables are mentioned in the title, hypotheses, and/or aims

$\square$ No

$\square$ Unable to determine

\section{Multiculturally-Focused Research Studies}

\section{METHODS \& PROCEDURES}

8) How were the aims of the study described?

$\square$ Exploratory

$\square$ Specific Hypotheses

$\square$ Both exploratory and specific hypotheses

$\square$ Unable to Determine

$\square$ Other/NA/Explain

9) How was the sample for this study selected?

\begin{tabular}{|c|c|}
\hline$\square$ Age/Generation & $\square$ Purposive | $\square$ Convenience | $\square$ UD \\
\hline$\square$ Gender & $\square$ Purposive $\mid \square$ Convenience $\mid \square$ UD \\
\hline$\square$ Race \& Ethnicity & $\square$ Purposive $\mid \square$ Convenience $\mid \square$ UD \\
\hline$\square$ Indigenous Heritage & $\square$ Purposive | $\square$ Convenience \\
\hline$\square$ Immigration & $\square$ Purposive | $\square$ Convenience | $\square$ UD \\
\hline$\square$ Language & $\square$ Purposive $\mid \square$ Convenience $\mid \square$ UD \\
\hline$\square$ Religion/Spirituality & $\square$ Purposive | $\square$ Convenience \\
\hline$\square$ Income/SES & $\square$ Purposive | $\square$ Convenience | $\square$ UD \\
\hline$\square$ Employment & $\square$ Purposive $\mid \square$ Convenience \\
\hline$\square$ Education & $\square$ Purposive | $\square$ Convenience \\
\hline$\square$ Sexual Orientation & $\square$ Purposive | $\square$ Convenience \\
\hline$\square$ Neighborhood & $\square$ Purposive | $\square$ Convenience | $\square$ UD \\
\hline$\square$ Ability/Disability & $\square$ Purposive | $\square$ Convenience | $\square$ UD \\
\hline
\end{tabular}

10) What type of data was used?
$\square$ Primary data
$\square$ Secondary data
$\square$ Unable to determine

\section{RESULTS}

11) Were results reported by cultural groups? (If "no", skip to \#14)

$\square$ Yes

$\square$ No

$\square$ Unable to Determine

$\square$ Other/NA/Explain 
12) Please check all cultural groups results were reported for:
$\square$ Age/Generation
$\square$ Race \& Ethnicity
$\square$ Income/SES
$\square$ Education
$\square$ Indig Heritage
$\square$ Neighborhood
$\square$ Ability/Disability

$\square$ Gender

$\square$ Religion/Spirituality

$\square$ Employment

$\square$ Sexual Orientation

$\square$ Immigration

$\square$ Language

13) How were results by cultural group reported?

$\square$ Text only

$\square$ Table/Figure only

Both

$\square$ Unable to Determine

$\square$ Other/NA/Explain

\section{DISCUSSION/CONCLUSION/LIMITATIONS}

14) If culture was not considered in this study, was this acknowledged as a limitation?

(If culture was considered, highlight NA)
$\square$ Yes
$\square$ Unable to Determine
$\square$ No
$\square$ Not Applicable

15) Were future lines of cultural research suggested?
$\square$ Yes
$\square$ No
$\square$ Unable to Determine
$\square$ Group not specified
$\square$ Age/Generation
$\square$ Race \& Ethnicity
$\square$ Income/SES
$\square$ Education
$\square$ Indig Heritage
$\square$ Neighborhood
$\square$ Ability/Disability

$\square$ Gender

$\square$ Religion/Spirituality

$\square$ Employment

$\square$ Sexual Orientation

$\square$ Immigration

$\square$ Language

\section{FORENSIC PSYCHOLOGY FOCUS AREA}

16) Please type in the keywords listed under the title/abstract of the article

$\square$ Keywords

$\square$ No Keywords listed 


\section{BIBILIOGRAPHY}

Altman, Douglas G. 1999. Practical Statistics for Medical Research. Chapman; Hall/CRC Press.

American Civil Liberties Union. (2019). Immigration detainers. Retrieved from https://www.aclu.org/issues/immigrants-rights/ice-and-border-patrolabuses/immigration-detainers

American Psychological Association. (2002). Guidelines on Multicultural Education, Training, Research, Practice, and Organizational Change for Psychologists. Washington, DC: Author. Retrieved from http://www.apa.org/pi/oema/resources/policy/multicultural-guidelines.aspx

American Psychological Association. (2017). Multicultural Guidelines: An Ecological Approach to Context, Identity, and Intersectionality. Retrieved from: http://www.apa.org/about/policy/multicultural-guidelines.pdf

Andrews, D. A., \& Bonta, J. (2003). The psychology of criminal conduct ( $3 \mathrm{rd} \mathrm{Ed.).}$ Cincinnati, OH: Anderson Publishing Company.

Antonius, D., \& Martin, P. S. (2015). Commentary: Mental health and immigrant detainees in the United States. Journal of the American Academy of Psychiatry and the Law, 43(3), 282-286.

Baldus, D. C., Woodworth, G., Zuckerman, D., Weiner, N. A., \& Broffitt, B. (1998) Racial discrimination and the death penalty in the post-Furman era: An empirical and legal overview, with recent findings from Philadelphia. Cornell Law Review 83, 1638-1770. 
Bartol, C. R., \& Bartol, A. M. (2017). Introduction to forensic psychology. Thousand Oaks, CA: Sage.

Bernal, G., Jime'nez-Chafey, M. I., \& Rodriguez, M. M. (2009). Cultural adaptation of treatments: A resource for considering culture in evidence-based practice. Professional Psychology: Research and Practice, 40, 361-368. https://doi.org/10.1037/a0016401

Black, S. (2012). Frequently cited journals in forensic psychology. Psychological Reports, 110(1), 276-282. https://doi.org/10.2466\%2F09.13.17.PR0.110.1.276282

Bobo, L. D., \& Thompson, V. (2006). Unfair by design: The war on drugs, race, and the legitimacy of the criminal justice system. Social Research, 73, 445-472. https://www.muse.jhu.edu/article/527464.

Brewer, R. M., \& Heitze, N. A. (2008). The racialization of crime and punishment: Criminal justice, color-blind racism and the political economy of the prison industrial complex. American Behavioral Scientist, 51, 625-644. https://doi.org/10.1177/0002764207307745

Carson, E.A. (2015). Bureau of Justice Statistics Bulletin: Prisoners in 2014. Washington, DC: Office of Justice Programs, U.S. Department of Justice. Retrieved from http://www.bjs.gov/content/pub/pdf/p14.pdf

Carter, R.T., \& Forsyth, J.M. (2007). Examining race and culture in psychology journals: The case of forensic psychology. Professional Psychology: Research and Practice, 38(2), 133-142. https://doi.org/10.1037/0735-7028.38.2.133 
Center for American Progress \& Movement Advancement Project. (2016). Unjust: How the broken criminal justice system fails LGBTQ youth. Washington, DC: Center for American Progress and Denver, CO \& Movement Advancement Project. Retrieved from http://www.lgbtmap.org/file/lgbt-criminal-justiceyouth.pdf.

Cho, S., Crenshaw, K., \& McCall, L. (2013). Toward a field of intersectionality studies: Theory, applications, and praxis. Signs, 38, 1-26. https://doi.org/10.1086/669608

Davis, R. C., Erez, E., \& Avitabile, N. E. (1998). Immigrants and the criminal justice system: An exploratory study. Violence and Victims, 13(1), 21-30. https://doi.org/10.1891/0886-6708.13.1.21

Donald, E., \& Ng, K.-M. (2014). A critical review of content-analytic papers in ACAand APA sponsored journals from 1980-2011. International Journal for the Advancement of Counseling, 36, 1-16. https://doi.org/10.1007/s10447-0139186-8

Drucker, E. (2011). A plague of prisons: The epidemiology of mass incarceration in America. New York, New Press.

Eberhardt, J. L., Davies, P. G., Purdie-Vaughns, V. J., Johnson, S. L. (2006). Looking deathworthy: Perceived stereotypicality of black defendants predicts capitalsentencing outcomes. Psychological Science, 17, 383-386. https://doi.org/10.1111/j.1467-9280.2006.01716.x

Edgar, J. (2012). A content analysis of race salience for juvenile populations in forensic journals. An unpublished dissertation. 
Erford, B. T., Miller, E. M., Duncan, K., \& Erford, B. M. (2010). Submission patterns: Measurement and evaluation in counseling and development author and article characteristics from 1990 to 2009. Measurement and Evaluation in Counseling and Development, 42, 296-307. https://doi.org/10.1177/0748175609354619

Etikan, I., Musa, S., \& Alkassim, R. (2016). Comparison convenience sampling and purposive sampling. American Journal of Theoretical and Applied Statistics, 5(1), 1-4. https://doi.org/10.11648/j.ajtas.20160501.11

European Committee on Crime Problems. (2012). Recommendation of the Committee of Ministers to member States concerning foreign prisoners. Retrieved from https://wcd.coe.int/ViewDoc.jsp?id=1965593\&Site=CM.

Fleiss, J. L. (1971). Measuring nominal scale agreement among many raters. Psychological Bulletin, 76(5), 378-382.

Garnette, L., Irvine, A., Reyes, C., Wilber, S. (2011). Lesbian, gay, bisexual, and transgender (LGBT) youth and the juvenile justice system. In F. T. Sherman \& F. H. Jacobs, Juvenile justice: Advancing research, policy, and practice (pp. 156-173). New York, NY: Wiley.

Gómez-Durán E., \& Jones R. (2018) Challenging language barriers. In K. Goethals (eds), Forensic Psychiatry and Psychology in Europe. Springer, Cham.

Hancock, A. (2007). Examining intersectionality as a research paradigm: Multiplication doesn't equal quick addition. Perspectives on Politics, 5, 63-79. Hays, P. A. (2009). Integrating Evidence-Based practice, Cognitive-Behavior Therapy, and Multicultural Therapy: Ten steps for culturally competent 
practice. Professional Psychology, 40(4), 354-360.

https://doi.org/10.1037/a0016250

Heilbrun, K., \& Brooks, S. (2010). Forensic psychology and forensic science: A proposed agenda for the next decade. Psychology, Public Policy, and Law, 16(3), 219-253.

Helms, J. E., Jernigan, M. M., \& Mascher, J. (2005). The meaning of race in psychology and how to change it. American Psychologist, 60, 27-36. https://doi.org/10.1037/0003-066X.60.1.27

Helms, J.L. (2009, March). Forensic psychology journal rankings. Paper presented at the annual meeting of the American Psychology-Law Society, San Antonio, TX.

Hubbard, D. J. (2007). Getting the most out of correctional treatment: Testing the responsivity principle on male and female offenders. Federal Probation, 71, 28.

Irvine, A. (2010). "We've had three of them": Addressing the invisibility of lesbian, gay, bisexual and gender nonconforming youths in the juvenile justice system. Columbia Journal of Gender and Law, 19(3), 675-701.

James, A. (2001). Making sense of race and racial classification. Race \& Society, 4, 235-247. https://doi.org/10.1016/S1090-9524(03)00012-3

James, S. E., Herman, J. L., Rankin, S., Keisling, M., Mottet, L., \& Anafi, M. (2016). The report of the 2015 U.S. transgender survey. National Center for Transgender Equality: Washington, DC. Retrieved from, 
https://www.transequality.org/sites/default/files/docs/USTS-Full-ReportFINAL.PDF

Kaeble, D., Maruschak, L.M., \& Bonczar, T.P. (2015). Bureau of Justice Statistics Bulletin: Probation and parole in the United States, 2014. Washington, DC: Office of Justice Programs, U.S. Department of Justice. Retrieved from http://www.bjs.gov/content/pub/pdf/ppus14.pdf

Landis, J. R., \& Koch, G. G. (1977). The measurement of observer agreement for categorical data. Biometrics, 33(1), 159-174. https://doi.org/10.2307/2529310

Loeber, R. \& Farrington, D. P. (1998). Serious and violent juvenile offender: Risk factors and successful interventions. Sage Publications: Thousand Oaks, CA.

Maschi, T., Hatcher, S. S., Schwalbe, C. S., \& Rosato, N. S. (2008). Mapping the social service pathways of youth to and through the juvenile justice system: A comprehensive review. Children and Youth Services Review, 30(12), 13761385. https://doi.org/10.1016/j.childyouth.2008.04.006

McAuliff, B. D., Hunt, J. S., Levett, L. M., Zelechoski, A. D., Scherr, K. C., \& DeMatteo, D. (2019). Taking the next steps: Promoting open science and expanding diversity in Law and Human Behavior. Law and Human Behavior, 43(1), 1-8. http://dx.doi.org/10.1037/lhb0000322

McHugh, M. L. (2012). Interrater reliability: The kappa statistic. Biomedica, 22(3), 276-682.

Mogul, J. L., Ritchie, A. J. and Whitlock, K. (2011). Queer (In)justice: the criminalization of LGBT people in the United States. Boston: Beacon Press. 
Motivans, M. (2019). Immigration, Citizenship, and the Federal Justice System, 19982018. U.S. Department of Justice, Office of Justice Programs, Bureau of Justice Statistics. Retrieved from https://www.bjs.gov/content/pub/pdf/icfjs9818.pdf

Padilla, J., Miller, M., \& Broadus, A. (2008). Analysis of Hispanic representation and conceptualization in psychology and law research. Behavioral Sciences \& the Law, 26(5), 655-670. https://doi.org/10.1002/bsl.818

Pettit, B., \& Western, B. (2004). Mass imprisonment and the life course: Race and class inequality in U.S. incarceration. American Sociological Review, 59, 151169. https://doi.org/10.1177/000312240406900201

Pew Research Center. (2019). Facts on U.S. immigrants, 2017. Retrieved from https://www.pewhispanic.org/2019/06/03/facts-on-u-s-immigrants/

Prins, S. J. (2014). Prevalence of mental illnesses in U.S. State Prisons: A systematic review. Psychiatric Services, 65, 862-872. https://doi.org/10.1176/appi.ps.201300166

Sampson, R. J., \& Lauritsen, J. L. (1997). Racial and ethnic disparities in crime and criminal justice in the United States. Crime and Justice, 21, 311-374. https://doi.org/10.1086/449253

Smedley, A., \& Smedley, B. D. (2005). Race as biology is fiction, racism as a social problem is real: Anthropological and historical perspectives on the social construction of race. American Psychologist, 60, 16-26. https://doi.org/10.1037/0003-066X.60.1.16 
Spade, D. (2006). Compliance is gendered: Struggling for gender self-determination in a hostile economy. In P. Currah, R. M. Juang, \& S. P. Minter (Eds.), Transgender rights (pp. 217-241). Minneapolis, MN: University of Minnesota Press.

Otto, R.K., \& Heilbrun, K. (2002). The practice of forensic psychology: A look toward the future in light of the past. American Psychologist, 57(1), 5-18. https://doi.org/10.1037/0003-066X.57.1.5

van de Vijver, F.J.R. \& Matsumoto, D. (Eds.). (2010). Cross-cultural research methods in psychology. New York, NY: Cambridge University Press.

Van Voorhis, P., Wright, E. M., Salisbury, E., Bauman, A. (2010). Women's risk factors and their contributions to existing risk/needs assessment: The current status of a gender-responsive supplement. Criminal Justice \& Behavior, 37(3), 261-288. https://doi.org/10.1177/0093854809357442 